\title{
Intelligent Data Analysis Approaches to Churn as a Business Problem: a Survey
}

\author{
David L. García · Àngela Nebot · Alfredo Vellido
}

Received: date / Accepted: date

\begin{abstract}
Globalization processes and market deregulation policies are rapidly changing the competitive environments of many economic sectors. The appearance of new competitors and technologies leads to an increase in competition and, with it, a growing preoccupation among service providing companies with creating stronger customer bonds. In this context, anticipating the customer's intention to abandon the provider, a phenomenon known as churn, becomes a competitive advantage. Such anticipation can be the result of the correct application of information-based knowledge extraction in the form of business analytics. In particular, the use of intelligent data analysis, or data mining, for the analysis of market surveyed information can be of great assistance to churn management. In this paper, we provide a detailed survey of recent applications of business analytics to churn, with a focus on computational intelligence methods. This is preceded by an in-depth discussion of churn within the context of customer continuity management. The survey is structured according to the stages identified as basic for the building of the predictive models of churn, as well as according to the different types of predictive methods employed and the business areas of their application.
\end{abstract}

Keywords Churn analysis · intelligent data analysis $\cdot$ computational intelligence $\cdot$ customer continuity management $\cdot$ literature survey

This research was partially supported by Spanish MINECO TIN2012-31377 research project.

David L. García

Department of Computer Science, Universitat Politècnica de Catalunya, Spain

Tel.: +34-93-4137796

Fax: +34-93-4137833

Àngela Nebot

Department of Computer Science, Universitat Politècnica de Catalunya, Spain

Tel.: +34-93-4137783

Fax: +34-93-4137833

Alfredo Vellido

Department of Computer Science, Universitat Politècnica de Catalunya, Spain

Tel.: +34-93-4137796

Fax: $+34-93-4137833$ 


\section{Introduction}

The ongoing processes of globalization and deregulation are changing the competitive framework in the majority of economic sectors. The appearance of new competitors and technologies entails a sharp increase in competition. It also entails a growing preoccupation among service providing companies with the creation of stronger bonds with customers in a context in which they are required to fight over their customer portfolios in increasingly shifting markets. Many of these companies are diverting resources away from the goal of capturing new customers and are instead focusing on retaining the existing ones, particularly those who represent a higher return on investment. In this context, anticipating the customer's intention to abandon, a phenomenon also known as churn, and facilitating the launch of retention-focused actions both may become elements of competitive advantage.

Data mining (DM) was originally conceived as a process for business analytics, organized as a succession of stages defined according to a methodology [85]. Intelligent data analysis (IDA), in the form of pattern recognition (PR), machine learning (ML), statistics and related approaches, remains at the core of DM. IDA approaches are key in several stages of DM, including data exploration for knowledge discovery $[85,25]$ and data modelling for tasks of prediction, classification, segmentation, or rule extraction, amongst others.

Despite the fact that DM has outgrown its original purpose, IDA techniques have proven useful over de last decades in their application to business problems [96, 64]. We should therefore expect these techniques, applied to market surveyed information, which is often readily available for service providing companies, to be of assistance in churn management processes.

This paper aims to provide the reader, be it a business analyst or a data scientist, with a thorough survey and review of churn analysis applications of IDA techniques reported in recent academic literature.

In Section 2, we first describe the concept of churn or supplier abandonment by the customer as a business problem in some detail. In order to do so, we discuss business concepts such as customer life-cycle, customer loyalty and customer continuity management.

Section 3 shifts the focus of attention to different aspects of the use of IDA techniques in churn management. We explore them from the point of view of DM, differentiating the consecutive stages of the mining process for building predictive models of abandonment, which include: data gathering and understanding, feature selection, design and development of the predictive model, and validation and evaluation of this model.

This is followed by a compilation of the reviewed literature in the form of tables, according to two main criteria: the predictive method used in the application and the business area to which churn analysis is applied. Then, a discussion of the surveyed studies is provided in Section 4 . It is again structured according to the four stages of the mining process for building predictive models of abandonment. All stages are illustrated and discussed using examples from recent churn analysis literature. General patterns for each of the stages are commented and some recommendations, both general and business area-specific, are made. The paper wraps up with some concluding remarks.

\section{Churn as a business problem}

In the scenario of global competitive pressure described in the introduction, the possibilities of commercial development and, consequently, of adding value to a company require prolonging the useful life of its existing customers and increasing their average consumption. The management of the different commercial development alternatives in mature markets is illustrated in Figure 1.

Customer retention requires understanding how customer loyalty construction mechanisms work, in order to anticipate customers' intention to abandon and facilitate the launch of retentionfocused actions as a result. This understanding enables defensive commercial strategies oriented to 
retain and create loyalty bonds in existing customers, an approach that is likely to be more effective and less costly than an aggressive strategy to expand the overall size of the market, attracting potential customers. The cost of losing profitable customers to fiercely competitive markets is making many companies shift their target from the massive capture of new customers to the preservation of existing ones.

However, this struggle for achieving customer loyalty collides with the grinding exposure to advertised offers from competitors that customers face on a regular basis. Furthermore, customers' market awareness is constantly on the increase and, as a result, so are their expectations.

Companies have their customers as their main assets and they are responsible for the definition and implementation of policies that allow them to reach and prolong their maximum commercial development potential. In other words, they must prolong the life expectancy of their customer portfolio as much as possible, ensuring its adequate development in terms of value through the implementation of suitable commercial actions for each one of the stages of their life-cycle ${ }^{1}$ (See an illustration of the stages of a customer life-cycle in Figure 2). Despite the fact that both dimensions in this figure: generated value and time of customer-company relationship, are strongly related in a unique Customer Value Management model, we understand that an appropriate development of customer's commercial value needs to guarantee its continuity first [27], although it is equally true that a proactive customer's value development has a positive influence on its relationship with the company: high purchase and high value customers use to have a longer lifetime value. Thereby, increasing customer's life expectancy should be the primary aim that determines and guides any posterior commercial action of value development.

The final objective is self-explanatory: the commercial relationship with customers -the valuable ones- must be kept and reinforced. For that purpose, companies should build strong customer defection-avoiding schemes. This is not to say that unprofitable customers should not be cared for. As supported by investigations in [35], companies should be aware of the fact that the abandonment of unprofitable customers by the supplier might lead to unintended negative impacts on the loyalty and attitudes of the retained valuable customers. As shown in this study, the increase of switching costs and satisfaction among the latter might not be enough to compensate for those negative impacts. Moreover, it may often be the case that the abandonment of unprofitable customers may have a significant economic impact that should be accounted for when quantifying lifetime customer value [36].

It should be borne in mind that companies and their customers are in a constant evolution that may lead to natural and unpredictable disruptions in the commercial relationship (change of home address, family life-cycle, change in interests, payment type, etc.). Thus, final success will not be based on lengthening customers' life-cycle in an unnatural fashion, but on ensuring that good customers do not leave prematurely.

\subsection{Customer continuity management}

The creation of loyalty bonds in customers requires a systematic approach to its management. The possible symptoms that might alert of a possible defection to the competition must be preventively anticipated, and this requires evaluation of their evolution over time. Therefore, the adoption of a suitable Customer Continuity Management (CCM) model [27] should make it easier for companies to critically review all aspects that might affect the construction of true loyalty bonds with customers, including policies for everyday management, both for the customer life-cycles and for the predicted and declared cases of customer loss (see Figure 3).

\footnotetext{
1 Through the increase in services used (up-selling); the increase in consumption or wallet share (cross-selling); the construction of stronger loyalty bonds; the proactive retention actions on customers who intend to leave the actual provider; the launch of new products and services (innovation) and/or the adjustment of commercial costs, giving each costumer as expected.
} 
The level of customer bonding and, as a result, their life expectancy is intimately bound to the level of customer satisfaction relative to the quality of the service provided by a company. The higher the level of quality of service that customers perceive, the stronger the loyalty bonds $[20,47,48,79,83,53]$. Thus, consumers who experience high levels of satisfaction about the service usually continue with their current provider.

However, and despite customer satisfaction having a positive influence on the level of bonding, it does not always suffice. There are numerous situations in which better service quality does not have a significant impact on consumer loyalty: for instance, customers that change mobile phone operators in spite of the fact that their current provider offers greater coverage; customers that fill up in slow petrol stations, with bad accesses and no additional services for the driver; customers who prefer to travel with certain airlines despite the continuous delays to their flights, etc. In consequence, there must be other factors, beyond satisfaction with service, influencing customer loyalty.

At this point, we introduce the concept of barriers to change as a construct that should mediate the satisfaction-loyalty relationship $[20,47,48]$. When the level of customer satisfaction with respect to different providers is similar, the level of bonding should be expected to depend, to a large extent, on the nature and strength of the barriers to change in place. The existing literature usually portrays the barriers to change in a negative sense, as difficulties and burdens -emotional, social or financial- that the customer must overcome when making the decision to change providers $[20,47,48,79,55,28]$. However, in a market place that is becoming increasingly deregulated and competitive, the understanding of the construction of barriers to change as bureaucratic, contractual and/or in some cases, as the result of the abuse of a dominant position, is a limited viewpoint. Barriers such as penalties when cancelling a given service; problems in the portability of mobile phone numbers; delays in the provision of the new service that are the fault of the old provider: all these are actions that are becoming steadily more regulated and penalized by the market and are not sustainable in the medium term.

To be sustainable, barriers to change must be built, like satisfaction, on customer perception. In this way, the active development of barriers to change becomes an excellence factor, in addition to satisfaction with the service, that is difficult to overcome by competitors in their attempt to attract the best customers. The construction of policies and procedures that maintain and improve excellence in both dimensions (satisfaction and barriers to change) should act as tools of prevention that protect customers from being lured by competitors.

However, not all customers need the same level of service; nor are they all prepared to pay the same for it, or to obtain it in the same way. Common sense tells us that it is not possible to fulfill completely, in an increasingly heterogeneous environment, the difficult task of developing the loyalty of all customers. For this reason, starting from the certainty that dissatisfied customers will always exist, companies must concentrate their efforts on the development of a broad-spectrum retention program, maintaining and improving those dimensions of the offer and barriers to change that most and best impact on the overall bonding of customers as a group. The objective is not to protect all customers, but rather as many of them as possible and, in particular, those who are most valuable to a given company.

It has to be born in mind that the effect of prevention procedures is never foolproof. Over the natural life-span of the customers, it is possible that external changes, such as the appearance of new products, variations in competitors' offers, technological changes; and/or internal changes (improvement in the customer's knowledge level or increase in his exigency, socioeconomic changes, etc.) occur that might affect customers' expectations and, as a result, their level of satisfaction. Companies must watch out for these changes to adapt their policies and procedures so that they can maintain and improve customers' opinions about the service on offer. The process of analyzing the dimensions with most impact on the satisfaction and the subsequent adjustment in commercial procedures and policies should become an ongoing process over time. 
On the other hand, and from an operational perspective, it is not possible, given the high cost involved, to ask all customers from time to time for their opinions (even more so in the case of companies with hundreds of thousands or even millions of active clients) on the satisfaction perceived of the service they are being offered and/or their level of bonding. Companies must therefore work with representative enough samples and develop, based on their analysis, appropriate commercial policies.

Customers' evolution must be tracked and the number of customers at risk of churning must be estimated. That is why companies must have a reliable prediction model (adapted to the market research and based on behavioural information systematically gathered by the company) that allows them to identify -with enough anticipation- those clients that show symptoms of propensity to switch service providers and, thus, launch efficient retention actions. Following with the medical metaphor, early diagnosis of the propensity to churn will reduce considerably the aggressiveness of the required loyalty bonding treatment and will increase the customer's recovery possibilities. In this context, the client's value (understanding as client's value the sum of his actual recurrent value and his potential value) becomes the fundamental dimension that will determine which type of therapy, proactive and/or reactive, should be applied at any time.

This business effort -measured in the form of discounts, benefits and privileges that are offered to the client so that she or he will dismiss the idea of changing providers- should be balanced against the customer's expected value. This means that there may be clients that the company will decide not to retain even if their intention to change is identified in advance, since the expected return on the prolongation of their customer life does not justify the cost of the necessary commercial action. Identical criteria can be applied when deciding recovery policies and actions for already lost clients. Note though that, as reported in [35], careless abandonment of the less profitable customers may lead to unexpected negative reactions from the valuable ones that companies aim to retain.

\section{Intelligent Data Analysis for churn management}

The design of CCM models has been suggested in the previous section as an adequate approach to the task of prolonging the life-cycle of company customers. Anticipating a customer's intention to abandon their current provider company should be considered a key element of any therapeutic strategy in churn management.

In this context, DM techniques, including IDA in the form of PR, ML, statistics and related approaches, as applied to market surveyed information, could and should play a key role in helping to understand how customer loyalty construction mechanisms work, and helping to analyze customers' intention to abandon from different angles, from exploratory characterization to outright prediction.

However, not all cases of churn are equally important, nor are they all predictable. According to the reasons behind it, abandonment can be classified in different typologies:

- Involuntary cancellation: It affects customers from which their current company withdraws the service (e.g., fraud, arrears). Generally, companies do not even consider these cancellations as abandonment for their records.

- Voluntary cancellation: It corresponds to customers who consciously decide to change provider. Two variants of this type can be considered:

- Circumstantial: Due to changes in the customer's circumstances which do not allow them to continue (change of address, inclusion in the company's social benefit plans, change of marital status, children, etc.). This cancellation is intrinsically unpredictable.

- Deliberate: It occurs when the customer voluntarily decides to abandon their current supplier for a competitor.

Here, we only consider this last scenario: voluntary and deliberate churn. In the remaining of the section we discuss the different stages of the standard process of design and development of 
a predictive model of supplier abandonment (customer abandoning the supplier). This literature will then be summarily organized in Section 3.2 and in the Appendix in the form of tables created according to two main grouping criteria: the type of predictive model used in the study and its particular business area of application.

\subsection{Building predictive models of abandonment}

The design and development of predictive models of supplier abandonment or churn can be divided into four general stages [21], as seen in Figure 4. The last three stages of this process form a cycle that is completed only if and when adequate prediction results are achieved. We will now take a closer look at each of these stages in turn.

Stage 1: Identifying and obtaining the best data. This might arguably be the most relevant stage in the construction of a predictive abandonment model. Experience shows that the quality and suitability of the available data determines the accuracy and predictive power of the resulting model. Different data combinations may be better or worse indicators for different problems and for different areas of business. Ultimately, it is a question of identifying the data that best fit the type of analysis being carried out. Only in this manner could useful and usable knowledge (in business terms) be extracted in subsequent stages of analysis.

This stage in the building of predictive models of abandonment would fit, from a DM process point of view, the phases of problem and data understanding. Bearing this in mind, and from a practical point of view, it is important to note that the predictive model should ideally be constructed on the basis of the available data gathered routinely by a company from its whole customer base, which can be an extremely costly process. Consequently, those data bearing most of the predictive power may not always be available. Companies, therefore, may often be faced by the trade-off problem of identifying the best possible data from what is available to them.

The process of understanding and interpreting the data is often difficult. Even though the data in each field of a database may seem self-explanatory and unambiguous, interpretation may be hampered by the use of specific and ad hoc company lingo, different numerical formats, or simply because their meaning is different from the apparently obvious. Given the usual lack of standards to facilitate this process at the company level, its success is largely based on good communication between database managers and the data analysts. In fact, these DM stages have not been duly documented in the majority of investigations carried out in recent years [34].

Stage 2: Selection of attributes. In this stage, the most appropriate attributes or features for prediction must be selected from those available to the analyst, which, in a supervised PR setting, which is the most common in the literature of churn IDA, would be those that minimize the classification or prediction error; in an unsupervised learning setting, which might address churn analysis as a market segmentation problem, would be those which best reflect the grouping or cluster structure of the data. From a DM process point of view, this stage would correspond to the phase of data pre-processing.

This pre-processing is paramount as it helps to reduce the dimensionality of the data so that only the important attributes are included for analysis, whereas the redundant, noisy and/or irrelevant ones are excluded [107]. As a result, the selected features are also much more likely to provide an easier interpretability, in practical terms, of the obtained solutions.

Feature selection in supervised settings is a problem that has been thoroughly studied throughout the years $[32,89,67]$, and providing a survey of selection methods is beyond the scope of this review. There are different feature selection criteria for the less frequently explored problems in unsupervised learning (e.g., clustering), although a number of variable ranking criteria are useful across applications, including saliency, entropy, smoothness, density and reliability [32]. 
Stage 3: Development of a predictive model. Once the best data available for analysis have been selected, the next stage of predictive model development entails the choice of the most suitable methods and techniques for building such model. This corresponds to the modeling phase in DM. In a simplified manner, a predictive model can be defined as one that extracts patterns from the available data in order to make inferences for previously unseen data or future situations [84].

In the area of abandonment prediction, the most commonly used modelling techniques, as reflected in the literature, include decision trees (DT), regression analysis [63] and artificial neural networks (ANN) [18], while in more recent years new methods such as support vector machines (SVM) have proven their adequacy $[17,13,106]$.

As later explained in Section 3.2, one of the criteria according to which our review of churn IDA literature is organized is the type of predictive model used for analysis. For the sake of simplicity, three general categories were considered: standard methods, computational intelligence (CI) methods and other alternative methods.

\section{Standard methods}

In this category, we consider two families of techniques, namely regression analysis from standard multivariate statistics, and DTs, which are algorithmic methods with close ties to statistics and which are considered here as standard due to their widespread acceptance for churn analysis applications.

- Regression analysis: A popular standard multivariate statistics family of techniques used by researchers dealing with the prediction of abandonment. It is stated in [72] that logistic regression's popularity in particular is due to its quick and robust results as compared to other classification techniques, added to its conceptual simplicity and its closed-form solution available for posterior probabilities.

- Decision Trees: Arguably, the most popular type of predictive model in business applications is the DT. In its different forms, it has become an important knowledge extraction method, used for the classification of markets from static data or for the classification of future events [77].

Popular choices of DT in churn data analysis include the C5.0 classification tree -a variant of the well-known C4.5-, which assembles classification trees by recursively splitting the instance space into smaller subgroups, according to an information entropy criterion, until only instances from the same class remain known as a pure node, or a sub-group containing occurrences from different classes known as impure nodes. The tree is allowed to grow to its full potential before it is pruned back in order to increase its power of generalisation on unseen data.

Another frequently used DT is the classification and regression tree (CART), constructed by recursively splitting the instance space into smaller sub-groups until a specified criterion has been met. The decrease in impurity of the parent node against the child nodes defines the goodness of the split. The tree is only allowed to grow until the decrease in impurity falls below a user-defined threshold. At this time the node becomes a terminal, or leaf node [5].

\section{Computational Intelligence methods}

CI methods provide, in one form or another, flexible information processing capabilities for handling real life problems. Exploiting the tolerance for imprecision, uncertainty, approximate reasoning and partial truth in order to achieve tractability, robustness, low solution cost, and close resemblance with human-like decision making, is the overall objective of CI methods [78]. Techniques that fall into this category include evolutionary computation (EC), ANNs and other ML techniques, fuzzy logic (see, for instance, [7] for an interesting clustering application) and their combinations, such as neuro-fuzzy systems [34]. We shall briefly describe them next.

- Artificial Neural Networks: ANNs are a family of ML models that have successfully been used to estimate complex non-linear functions and have been applied to many types of churn 
problems with high predictive accuracy, mostly related to classification, and prediction [53, $45,3]$. An important factor when considering the practical use of ANN is that they do not necessarily uncover patterns in an easily understandable and interpretable form [1], which may limit the scope of their implementation in practice, unless they are accompanied by sound strategies of feature selection from stage 2.

- Support Vector Machines: This ML method, based on statistical learning theory, is able to optimally separate two class of objects (e.g., churners and retained customers) through the generation of a multivariate maximally separating hyperplane. Its theoretical basis was established in [8] and [15]. SVMs have been widely used in recent studies due to notable advantages such as a lower number of controlling parameters and good generalization capability [12, 40]. This method, though, remains difficult to interpret in terms of the input attributes [86] and may perform poorly in problems with strongly overlapping classes.

- DMEL (Data Mining by Evolutionary Learning): This EC algorithm aims to overcome the limitations of interpretation and understanding of the results obtained through some CI techniques -in contrast with the clarity of the if-then-rules obtained through DT, for example-. DMEL uses a non-random initial population based on first order rules. Higher-order rules are then obtained iteratively using a genetic algorithm (GA) type process. The fitness value of a chromosome uses a function that defines the probability that the attribute value is correctly determined using the rules it encodes. The likelihood of prediction is estimated and the algorithm handles missing values.

- Bayesian networks: These are probabilistic graphical models that lay somewhere in between multivariate statistics and CI. A Bayesian network can be seen as a probabilistic "white box" that represents conditional dependencies over a set of discrete stochastic variables as a directed acyclic graph. As such, this type of model could nicely represent the possibly complex interdependencies between variables leading to the churn phenomenon.

Other alternative methods

This category does in fact include methods that could at least partially fit into the previous categories, but which have scarcely been used in the context of churn analysis. They can thus be considered as somehow exotic in this context and include: Ensemble Learning in different forms, semi-Markov processes, mixture transition distribution models and goal-oriented sequential pattern algorithms.

Stage 4: Validation of results.

This is again a key to the success of any data-based churn analysis and corresponds to the evaluation phase in DM. Some of the most commonly used methods for model validation in the churn analysis literature are:

- Cross-validation: Most suitable in those cases in which data are scarce. In its most simple version, a single split of the data is generated (such as the 70/30 used in [45]; the 70\% of cases used as training set and the $30 \%$ remaining as validation set). Cross-validation is based on the principle of using the available data for both training and validation. Several more sophisticated cross-validation methods have been proposed in the literature [34], including:

- K-fold cross-validation: The learning set is randomly partitioned into K subsets of equal size. Each individual subset is then used in turn for validation, while the rest of the data are used for training. In the extreme case of choosing single case folds, the procedure is called leave-one-out cross-validation.

- Monte Carlo (or repeated random sub-sampling) cross-validation: The learning set is repeatedly divided into two random sets, one of which is used for training and the other for validation. Not all cases are necessarily chosen at any point for validation. See, for instance, [93] for an application of the method to churn analysis. 
- Separate validation dataset: Several authors [21, 5, 81] have successfully used single validation sets separated from the training sets in the validation of their predictive models of abandonment. This method should only be acceptable in those cases in which data availability is not an issue.

When testing the validity of a model, or comparing the results of different methods, the following set of indicators are the most commonly used [63, 22]:

- Accuracy, Sensitivity and Specificity: For classification models with a binary target variable. Accuracy measures the ratio of correctly classified observations (churn or not-churn) to the overall number of cases. Sensitivity instead measures the ratio of correctly predicted events (i.e., correct churn predictions) to the total number of events (total of churn cases), whereas specificity measures the ratio of correctly predicted non-events (i.e., not-churn) to the total number of non-events (total of not-churn cases). Although accuracy is intuitive and commonly used to compare prediction methods $[63,102,76]$, it is not considered to be an optimum figure of merit for churn modelling because it is unreliable in a situation of class imbalance [60], which is by far the most common in this application area [82].

- Area under the Receiver Operating Characteristic (ROC) curve: ROC is a function of the sensitivity versus 1 - specificity for all values of the classification threshold and it has been widely used in the churn prediction literature $[43,17,69,31,76,60,22,104,106]$. Its Area Under the Curve (AUC), unlike accuracy, evaluates the ability of a classifier to distinguish between classes based on the predicted class membership probabilities and is therefore suitable for imbalanced classification problems [57].

- Lift Chart: This technique focuses on the segment of highest-risk customers, arranging them into deciles based on their predicted probability to churn and comparing its results with the rest of the cases. The Lift Chart has also been commonly used in recent studies [69, 31, 76, 16, 22]. It can be found in two different forms:

- Top decile Lift (TDL): Is the churn rate in the top decile of ordered posterior churn probabilities over the churn rate in the total customer population [60].

- Lift Index (LI): Is the weighted index of the correctly predicted churners, ranked by its posterior churn probability [19].

- Loss function: Calculated on the basis of customers' Life Time Value (LTV), this method indicates the loss caused by the error of the model, considering the effect of misclassified customers. Some examples can be found in recent work [76, 29].

\subsection{A summarized review of the literature}

We have compiled the reviewed literature in a number of detailed summary tables: 2 to 14 , which can be found in the Appendix. They list the main references in recent literature (roughly over the last 15 years and including mainly peer-reviewed journal publications, although some conference publications and $\mathrm{PhD}$ thesis have also been included for their specific interest) that address the problem of building predictive models of abandonment. Following the same scheme of stages proposed for the previous section as guiding index, these tables show: the references to the articles; the type of data used in the analysis; the source from which those data were obtained; the attribute selection technique employed; the possible use of time series data in its definition; the techniques used to develop the predictive models; and, finally, the methods used for validation, if any.

These detailed tables are organized according to two main criteria:

- According to the predictive methods used: Tables 2, 3 and 4 for standard techniques; tables 5, 6 and 7 for CI methods; and tables 8 and 9 for alternative ones.

- According to fields of application: Tables 10 and 11 (telecommunications), 12 (banking), and 13 and 14 (other areas of application). 
Here, we show a single summary table structuring the reviewed publications according to, first, business area and subsequently, type of analytical method (standard methods, CI methods and other alternative methods).

[Table 1 here]

\section{Discussion}

This section of discussion of the reviewed literature is articulated, first, according to the four stages for building predictive models of abandonment described in section 3.1. Comments and recommendations are made for each of these stages, followed by specific comments and recommendations for, in turn, the two main blocks of industries in which the tabular results are organized in the appendix, namely Telecommunications and Banking.

\subsection{Stage 1: Identifying and obtaining the best data.}

A selection of different data requirements and motifs for the analysis of churn can be drawn from the recent literature. The most relevant are detailed next.

A large group of studies base their models of abandonment prediction on customer use/consumption variables: Madden and colleagues [68], in their customer retention model for the Australian ISP (Internet Service Provider) industry, classified and used four categories of variables: economic, use, ISP choice and demographics. $\mathrm{Ng}$ and Lin suggested in [73] the use of customer consumption for identifying churn in the telecommunications market. In [100], it was concluded that the purchase of products and services can be better predicted using historic purchasing data. This view was backed in [39], where it was proposed that the analysis of transaction data, through historic account and customer data, could provide us with clues to identify the best incentives for a bank to offer its customers and to improve the marketing strategy. Data on customer usage have also been used to identify the behaviour of website-using customers [46] and to predict repeat purchasing by mail [94].

More recently, customer usage/consumption data have been complemented with other variables as key elements in identifying abandonment. For instance, in a study of customer deflection in the wireless telecommunications market [87], customer data were grouped into four types: demographics, usage level, quality of service and marketing features. This method was supported in a more recent study in the same sector [109]. Still in the field of telecommunications [72], Neslin and Gupta classified the selected variables into three main categories: customer behavior (minutes of use, revenue, handset equipment, trends in usage), company interaction data (calls to customer service) and customer household demographics (age, income, geographic location, home ownership), similar to the ones used in [43]. Hung and colleagues considered in [44] that the most significant variables for churn prediction in the mobile telephone industry are: demographic data (age, penetration rate, and gender), payment and account data (monthly quota, billing amount, arrears account), call details (call duration, call type), and customer service data (number of PIN number changes, number of blocks and suspensions). In their research about abandonment of the subscribers of a newspaper publishing company [17], Coussement and Van den Poel grouped customer data into four groups: subscription data (time since last renewal, monetary value, product), socio-demographics (age, gender), client/company interactions (number of complaints, time since the last complaint, responses to marketing actions) and renewal-related variables (days between subscription renovation and expiry date). More recently, data from credit card holder's in a Chinese bank were used in [75] and [102] to predict their abandonment, with a combination of usage variables (daily balance, abnormal usage, limit usage, revoking pays, transactions, etc.) and customer personal information. 
Stage 1: General recommendations: Some interesting conclusions can be drawn from the way the reviewed studies addressed stage 1 of the prediction model building process. The types of data gathered for analysis are quite varied and, to some extent, depend on the area of application. Overall, they do not seem to depend on the type of analysis technique applied in the study. Usage, socioeconomic and demographic variables predominate, and the use of RFM attributes is quite common. Curiously, given their likely predictive power, very few studies resort to analysis of standard data concerning quality of service or customer satisfaction, such as the SERVQUAL (e.g. in [3]) This is probably due to the difficulty of obtaining this type of information from customers (in comparison with, for instance, usage or socio-demographics), but perhaps also due to a lack of awareness of their usefulness as predictors of churn.

Another key issue is the fact that churn should be treated as a dynamic process that naturally evolves over time. For this reason, it is surprising that most of the studies are either static from the point of view of the data gathered for analysis (that is, most of the investigated data are market snapshots that lack information on its evolution), or unclear about the periodicity of the surveyed data, or used data that were averaged over time. Even among those studies that used data collected over time, many just cover a few months, making it difficult to discount seasonality effects. Some exceptions include the impressive 77 years of data from a financial services company that were analysed in [95]; the 30 months of data used to create the model plus 12 months of data for prediction used in [17]; the $17+4$ months in [16]; the 18 months in [38]; and the $12+12$ months periods used in [102], [76] and [13]. Again, this could be at least partially justified by the cost and difficulty of gathering consistently homogeneous customer data over long periods of time in rapidly changing scenarios.

Beyond the problem of choosing the most adequate set of data attributes, the paradox is that, as remarked in [95] and corroborated in [31] a decade later, few studies, even if using longitudinal surveys, make use of dynamic analysis models. Little work in churn analysis adventures beyond limited time windows both for the data to be modeled and for the predictions. It has been proposed [31] that the most natural framework for this problem is longitudinal data analysis and its related methods such as survival analysis (in their study, using Cox regression), that is, a dynamic analytical framework that allowed to allocate customer retention efforts across time and identify early indicators of attrition. The design and development of such dynamic models is one of the most important pending challenges in churn analysis. A very interesting example of a proper dynamic analysis of churn can be found in recent work by Bose and Chen [7].

Stage 1: Specific recommendations per industry.

Telecommunications: Usage data seem to be the common denominator of recent studies in this business domain $[73,106,93,7]$ and, as seen from the previous paragraph, these type of data are often complemented and enriched using demographics, socio-economic and marketing information.

Beyond that, recent technological advances have allowed to add a new type of data to the churn prediction mix: those generated by the customers' social communication networks, which could be analyzed under the conceptual framework of social commerce [30]. Sharing a somehow similar outlook on the problem, Kim and colleagues [52] developed procedures for churn prediction by examining the communication patterns among service subscribers, whereas Verbeke and co-workers [98] developed relational classifiers based on intercommunication graphs that allow to incorporate social network effects within a churn prediction model. This social communications network information could be easily added to the data mix in other industries beyond telecommunications, mostly those with strong internet presence.

Banking and financial services: Interestingly, the banking sector seems to take a much narrower approach to the identification of the best data for churn analysis, at least as compared to telecommunications and other industries. An example of this is the fact that number of churn studies in this review, mostly not related to banking and finances and including [39, 94, 80, 38, 101, 49, 65, 66, 13, 69] 
agree in suggesting the use of three groups of variables, globally known as RFM (Recency, Frecuency and Monetary variables):

- length of time since last purchase,

- frequency of use,

- economic expense effected over a certain time period,

as a source for the prediction of the churn probability. Note that most of these studies are in the areas of direct marketing and retailing, with the only exception of [39], which is an application to banking. Bose and Chen [6], when discussing direct marketing, stated that RFM variables are amongst the strongest performing variables in explaining future customer behavior. Nothing prevents the banking sector from using variations of RFM to enrich their churn analysis processes, especially given that modern banking often provides their customers with extra services that are not that far removed from the retail sector.

\subsection{Stage 2: selection of attributes}

Stage 2: General recommendations The investigation of stage 2 of the prediction model building process provides a really mixed picture in the reviewed literature. Many studies do not even consider attribute selection, while quite a few others justify the selection not on the quantitatively demonstrated impact of the data on the prediction but, instead, on domain knowledge (using attributes that have shown relevance in previous similar studies) or expert knowledge in the field (again, trusting prior experiences). Even among those investigations using some form of attribute selection, this often takes a very simple form, far from the state-of-the-art in the field (e.g., $R^{2}$ statistic coefficient, z-test, collinearity measure, Fisher score, etc.) and only in a few cases, the attribute selection technique is intrinsically associated to the modelling technique of choice (e.g. DTs $[21,73,56]$, RFs [17], ANNs [106], or SVMs [24, 56]).

This is a worrisome picture for the following reasons:

- Almost any business domain is becoming data-dependent in most of its processes and, therefore, more and more data attributes are likely to become available for a process such as abandonment prediction. This could be particularly true for those industries whose environment is the internet, such as web retailers. With the increase of information availability, comes a harder problem of selection of the adequate attributes to include in the analysis of supplier abandonment by the customer. As a result, the use of adequate procedures of attribute selection should become compulsory.

- There is nothing intrinsically wrong in the idea of using domain knowledge or expert knowledge in the specific business area. Much is to be learnt from prior experiences, but excessive reliance on prior experience may come with a higher risk of negative bias on the selection of attributes for the churn problem, as it might prevent from using attributes whose relevance might not be obvious to the human expert, but could still be found by data-based quantitative attribute selection methods.

- It is particularly unusual that such a small number of the reviewed studies using CI methods resort to attribute selection procedures, given the huge effort in this direction that has been made in the CI field. There are countless selection procedures specifically devised for any of the CI methods that have been employed in the reviewed churn analysis studies [32,67].

\section{Stage 2: Specific recommendations per industry}

Telecommunications: As seen in the previous section, the reviewed studies of churn analysis in the telecommunications sector are precisely characterized by a rich usage of data attributes, including usage data and often also using demographics, socio-economic and marketing information. 
This complex mixture of attributes would be enough motivation for the use of attribute selection procedures. Not using such procedures would entail running a few risks, including:

- The combination of datasets with a large number of cases (becoming more and more common in this field) and a large number of attributes may become burdensome from a computational viewpoint, specially for complex modeling techniques.

- Many of the available attributes maybe uninformative for prediction purposes, or redundant, negatively affecting the prediction capabilities of the churn prediction models.

- Without appropriate attribute selection, it becomes impossible to ascertain which attributes are the most relevant for churn classification and prediction. This becomes an easily avoidable limitation for knowledge extraction in the domain and precludes experts from saving unnecessary data gathering efforts.

For all these reasons, it is strange that a majority of the reviewed studies in the area of telecommunications either do not report any attribute selection at all or base the selection on expert and domain knowledge. In both cases, this is tantamount to not performing any data-based quantitative attribute selection. Only a minority of papers report the use of either statistical techniques (such as the $R^{2}$ or the Fisher score) or methods associated to non-traditional models. The obvious recommendation here would be to encourage researchers in the area to take attribute selection seriously as an almost compulsory part of the DM process oriented towards novel knowledge discovery. An example of proper and intensive attribute selection process using CI methods can be found in [106].

Banking and financial services: The banking and financial service sector provides us with the opposite side of the coin in terms of attribute selection, when compared to telecommunications. Even though there are still too many papers with either no attribute selection at all or a selection based only on expert and domain knowledge, the majority of the reviewed publications have used quantitative selection methods based on either statistics or embedded in the own modeling process. Further good news is that the most recent publications of churn analysis in banking seem to be paying adequate attention to this issue; examples of these are the detailed methods that can be found in [24] and, again, in [106].

\subsection{Stage 3: Development of a predictive model.}

The following lists provide a non-exhaustive overview of both the more traditional and the CI methods most used for predictive churn modelling.

\section{- Regression analysis:}

Regression analysis was used in [71] and [70] to link customer retention with satisfaction and its attributes in the fields of wireless telecommunications and private banking, while Kim and Yoon [51] used a logistic regression (logit) model to determine subscriber churn in the telecommunications industry, based on discrete choice theory (study of behaviour in situations where decision makers must select from a finite set of alternatives). In the same field, logistic regression was also used in [60], [62] and [93] to predict abandonment.

There are regression models specifically suited to the analysis of longitudinal data such as Cox regression, from the area of survival analysis, which was recently used in [31] as a natural framework for dynamic attrition studies.

In other studies $[11,17]$, logit models were used to predict abandonment of a Pay-TV operator and a newspaper publisher, comparing them with more novel methods: Markov chains in the first one and SVMs in the second. In the first case, logit models showed better accuracy while, in the second case, SVM only showed a better performance when an optimal parameter-selection procedure was applied. Huang et al. [45] and Lee et al. [59] proved that logistic regression outperformed ANNs, DTs and other methods in their churn prediction studies. 
More recently, multiple criteria decision models were used in [102] to evaluate the accuracy of 12 different algorithms -including logistic regression, multiple DT algorithms, and different Bayesian networks - when predicting churn on a bank's credit card holders. It was found that logistic regression yielded the highest predictive accuracy. Logistic regression and DTs were later used in [76] to forecast credit card customer defection, reporting a better performance of logistic regression.

- Decision Trees:

The literature contains quite a few examples of DTs for the construction of predictive models of abandonment. Datta and colleagues [21] carried out research in the area of churn prediction and developed a model that they called Churn Analysis Modelling and Prediction (CHAMP). CHAMP also uses DTs to predict customer churn in the telecommunications industry. The C4.5 method was chosen in [73] to automatically generate classification rules for the purpose of identifying potential defectors, while C5.0 was recently applied to churn analysis in telecommunication markets in [93].

In the analysis of wireless telecommunications markets, the performance of DT, ANN and logistic regression was compared in [45]. This study stated that the DT showed slightly better accuracy over the other methods (however, the authors affirmed that these results do not prove DT to be the best choice in all cases). This conclusion is supported by [71], [26] and [72]. These models can also been used for the purpose of rule extraction. An example of the use of Naïve Bayes Trees for rule extraction in the credit card business of the banking sector can be found in [24]. DTs have also been successfully applied in recent years to problems such as email users churn prediction [74], supplier selection [105], broadband internet users churn [41], churn in telecommunications companies [44,62], and credit card users churn [102, 56, 76, 24].

Computational Intelligence methods

\section{- Artificial Neural Networks:}

ANNs have been reported [21] to be still scarcely being used by companies in their day-today operations. In spite of that, many authors have used ANNs in an entrepreneurial setting for churn analysis $[64,44,84,56,10,33,92,42,109,72,95,29]$ due to their high predictive accuracy. In a recent study, Tiwari and colleagues [91] described a novel ANN method which predicted customers that were likely to be churn in the future, with less time margin than previous models.

\section{- Support Vector Machines:}

Several studies [90, 97, 61, 93] have used SVM methods to predict churn in the telecommunication sector. It has also been applied to the analysis of churn of newspaper subscribers [17], concluding that SVMs outperform logistic regression as a predictive method. This technique has also been used in [106] as base classifier in an ensemble model applied to the analysis of churn in both the telecommunications and banking sectors.

- DMEL (Data Mining by Evolutionary Learning): DMEL was used to predict churn in the telecommunications industry in [1]. More recently, Yeshwanth et al. [108] used a hybrid model to predict churn in mobile networks customers. They combined a pre-processing based on DT algorithms with a GA classification process.

- Bayesian networks: An attempt to estimate whether a new customer will increase or decrease future spending was reported in [2]. A Bayesian network was defined in this study as a probabilistic "white box" that represents a joint probability distribution over a set of discrete stochastic variables. Verbraken and colleagues [99] have recently continued this work by testing the predictive power of a number of Bayesian Network algorithms in churn analysis and proposing a feature selection method based on the concept of the Markov Blanket. Bayesian Networks have been successfully applied in recent studies of churn forecasting in the field of telecom industry [54] and in banking [102]. 
Other alternative methods

- Semi-Markov processes: They were used in [46] to create a model that considers e-customer behaviour. The discrete-time semi-Markov process was designed as a probabilistic model for use in the analysis of complex dynamic systems. It has also been used in [88] to study customer retention.

- Mixture transition distribution (MTD): Prinzie and Van den Poel [81] introduced a mixture transition distribution (MTD) to investigate purchase-sequence patterns. The MTD was designed to allow estimations of high order Markov chains, providing a smaller transition matrix facilitating managerial interpretation.

- Goal-oriented sequential pattern: a novel algorithm for identifying potential churners using association rules that identify relationships amongst variables was introduced in [14]. The authors defined a two-step process for finding out association rules. In the first step, the large item set (attribute-value pairs) is defined, requiring compliance with certain minimum conditions of support and minimum confidence defined by the researcher. In the second stage, an A Priori algorithm is used to explore the rules of association.

Stage 3. General recommendations: In this stage, the key issue is, precisely, the choice of the most adequate model or models (separately or in combination) for churn analysis.

From the summary Figures 5 and 6, it is clear that two of the standard methods are, by far, the most popular ones in recent literature: DTs and Regression Analysis. Their reasonable predictive accuracy is arguably the main reason behind the fact that more than $46 \%$ of the reviewed methods (see Figure 5, left) belong to these categories. They are mentioned in more than $70 \%$ of the analysed literature, acting as a benchmark to compare the results of other methods, or as the main predictive method. These methods have remained popular over the years, even increasing to a $51 \%$ share of the references published in the last 5 years (see Figure 5, right).

Further reasons to explain this popularity include their ease of implementation and availability of standard commercial software, but, perhaps more importantly, their transparency: the outcomes of both families of methods can easily be interpreted in terms of the attributes used to create the model; as a result, business rules to explain the churn phenomenon are reasonably easy to come by. In the particular case of DT, such rules take an attractive hierarchical form resulting from the tree-like model that branches according to specific attributes.

For their part, Computational Intelligence methods are also reasonably well accepted but still a bit of a novelty despite their long-standing record in many other application fields, including business [96, 64]. ANNs are the most commonly used ones (in 16\% of the reviewed literature), although in decline over the last few years. Their proficient predictive ability turns them into very attractive methods for researchers, but their lack of straightforward interpretability may slow their usage down in entrepreneurial environments [103, 2]. Such lack of interpretability is often the result of the nonlinear nature, which confers them with great modeling flexibility at the price of obscuring the relationship between the outcome and the data attributes. The adoption of CI methods in this area may also be slowed down by the lack of clear standards for their implementation.

Finally, the denominated "alternative methods", less specific and constantly improving, have only a marginal role $(17,2 \%$ of the studied literature in recent years) as methods of choice in supplier abandonment modelling.

Despite the obvious importance of such approach, comparative analyses in which the more traditional statistical methods are exhaustively compared with CI techniques are still uncommon in this application field [50, 93]. Such lack of comparisons limits the possibility of properly assessing the relative virtues and limitations of each of the methods.

A sound alternative to model comparison is Ensemble Learning, in which the predictions yielded by each of the models (learners) in the ensemble are combinations of the individual predictions of multiple algorithms. They have shown strong and robust prediction performance in many appli- 
cation areas. According to the combination of algorithms, the most popular ensemble learning methods in the field (although not the only ones; see for instance [106] and [93]) are:

- Random Forest (RF): It is a combination of Bagging [9], Random Subspace Method [37] and CART DTs [5]. RFs solve the high instability that hampers the use of DT and they have been used in several marketing research studies $[11,10,58]$ due to their high predictive performance and robustness to outliers and noise. Research about churn in newspaper subscribers [17] found that RF outperformed SVMs and logistic regression, and its usefulness was recently confirmed when predicting abandonment in the online gaming industry [16].

- GAMens: A combination of Bagging and Random Subspace Method (RSM) with Generalized Additive Models (GAM). The latter $[17,4]$ is a flexible technique for nonparametric regression. Recent work [23] has proven that GAMens can be competitive with RF in accuracy. More recently, they proved the predictive ability of this method applied to problems in several industries such as supermarkets, banking and telecommunications [22].

\section{Stage 3: Specific recommendations per industry}

Telecommunications: From an industry of application viewpoint, the reviewed literature reveals (see Figure 6, left) that telecommunications is the more active sector in terms of churn prediction modelling research ( $46 \%$ of the publications apply to this sector), followed by banking, found in $23 \%$ of literature. This makes sense, as churn is a much more pressing concern in the very volatile telecommunications market.

The profile of analytical model choice revealed by the graphics in Figure 6 (right) is quite interesting, as it indicates that telecommunications is, out of the reviewed sectors, the one in which less traditional models are being tested. This could perhaps be explained by the fact that banking is, by comparison, a more mature type of business with a long-standing tradition of use of statistical methods (which is a similar situation to the one observed in clinical medicine, in which statistical methods are still very prevalent). It is also curious to note that telecommunications includes a majority of studies in which several different techniques are compared or combined, which is a very positive approach. Combining both previous thoughts, an specific recommendation for this sector would be the integration of multivariate statistical approaches in the comparison and combination of methods for churn analysis.

Banking and financial services: It can be observed from Figure 6 (right) that in banking and financial services, Alternative methods are extraordinarily prevalent, much in contrast with the figures for the telecommunications sector. The suspicion that such contrast in the type of model choice is mostly motivated by the internal inertias of each industry is impossible to avoid, given that the churn problem itself is not that industry-dependent and the type of analyzed data does not justify the use of radically different methods.

The relative scarcity of the use of CI methods in this sector is somehow surprising, given that it was precisely in banking and financial services that CI scored some its first extremely successful real-world implementations, pioneering commercial software in the 1990's for problems such as bankruptcy prediction and credit scoring, amongst others [96]. Churn analysis in banking and financial services could, an perhaps should, benefit from the use of this accumulated knowledge and the resulting best-practice guidelines. This would also benefit from a more integral DM approach to data analysis that embedded the attribute selection procedures of stage 2 and robust validation techniques from stage 4, an integration that is usually straightforward in CI methods.

\subsection{Stage 4: Validation of results}

Stage 4: General recommendations The last stage of the prediction model building process, the validation of results, reveals that the literature in the field is far from agreeing in any standards. 
The dominating evaluation metric is the accuracy, which is often inadequate in situations of class unbalance, that is, when the prevalence of one of the classes is much higher than that of the rest. Needless to say, this is the most common scenario in churn analysis, where the number of churning cases is often much lower than the number of non-churning cases. Even though, sensitivity, specificity and the related precision, recall and AUC measures, which are much more adequate metrics in situations of class unbalance, are also used in quite a few studies. Lift charts are also quite commonly used. Note that sensitivity should be given special relevance in this context, as it measures the ratio of correctly predicted events (correct churn predictions) to the total number of events (total of churn cases). In most real scenarios, service providers should strive to maximize this metric, because correctly detecting the propensity of abandonment, which is a relatively uncommon event, is the most difficult task in churn analysis, but also the most important one for churn management.

Surprisingly, many studies do not seem to include any form of validation explicitly, something that should be compulsory if we aim to assess the ability of the model to generalize its results to unseen data. Such requirement should be specially relevant in churn analysis, in which the main goal is inferring the potential supplier abandonment of out-of-sample customers. This is a surprising finding, given that data scarcity is not a problem for any of the problems under analysis and, therefore, there is no barrier for the definition of a proper training-validation-test setting.

Out of those studies using validation, quite a few make use of different forms of cross-validation. The use of separate subsets for the three-way process of building, validating, and testing the model (which is the most appropriate and robust approach of validation) seems to be rarely considered in this area. This means that many of the reported results risk being, at best, over-optimistic estimations, or, at worst, or strongly biased and unreliable ones.

\section{Stage 4: Specific recommendations per industry}

Telecommunications: The use of appropriate validation seems specially important in churn analysis for the telecommunications sector. This is because of its higher levels of customer volatility and its lower switching barriers, which should make the adequate assessment of out-of-sample customers a more pressing concern. From Tables 10 and 11 in the appendix, it is clear that cross-validation is the most favoured strategy, but still a few studies only report a single training/test data split, which is a clearly sub-optimal validation strategy that risks biasing the results, undermining our confidence on their reliability. Even worse, quite a few studies in this field completely ignore the validation strategy, which means that their results could easily be over-optimistic as they might just reflect an over-fitting of a very specific and not necessarily representative data sample.

Another issue that demands attention in this area, related to one of the previous general recommendations, is that only a handful of the reviewed papers pay attention to the calculation of the sensitivity or related performance metrics.

Banking and financial services: Customers in banking and financial services might be far less volatile than those of telecommunication service providers. This, in principle, could mean that population samples are likely to be more stable and, therefore, models of such populations are less likely to be affected by data over-fitting; that is, out-of-sample estimations are bound to be more similar to the in-sample ones. Having said that, it is still surprising the extent to which many churn studies in this area do not provide any proper validation strategy for their models. Only one of the reviewed papers [24] resorts to a standard complete training-validation-test strategy with 10 -fold cross-validation. On a more positive note, most studies (specially the most recent ones) use adequate evaluation metrics, including sensitivity, specificity and AUC. 


\section{Conclusions}

Supplier abandonment is one of the main problems faced by service-providing companies in rapidly changing and extremely competitive mature markets. This is a problem that can only be addressed through personalization strategies oriented to retain valuable customers. When the market base is large, such personalization is only feasible as a data-intensive business analytics problem.

In such a scenario, a DM methodology based on IDA may become a useful knowledge and information management tool for knowledge extraction from domain data. This paper has surveyed and reviewed recent literature in which the use of IDA to build predictive models has been proposed to address the churn problem, with a (non-exclusive) focus on the use of CI techniques. Importantly, this literature has been reviewed according to the different stages of DM implementation, from data gathering and understanding, to predictive model validation. Different business areas of application have also been independently considered, with a focus on telecommunications, banking and financial services. Publications in the field are abundant and we have tried to narrow the scope of the review by prioritizing journal publications and covering the period 2000-2015. The reviewed studies are scattered in a large number of international journals (over 20), although two of them stand out for the special attention paid to the problem of churn analysis, namely Expert Systems with Applications and the European Journal of Operational Research.

From the existing literature, the relevance of adequate data gathering and attribute selection procedures becomes evident. It is also clear that no particular IDA method has the upper hand in terms of results, which means that the choice of method is very problem-dependent. It must be noted, though, that there are trends in the choice of methods that seem to be motivated by nothing more than their popularity in a given application area. An example of this is the preponderance of CI techniques for churn analysis in the banking sector, due to the fact that this sector pioneered the use of CI in the business world to tackle problems such as risk assessment, credit scoring, or bankruptcy prediction, to name a few [96].

\section{References}

1. Au WH, Chan KC, Yao X (2003) A novel evolutionary data mining algorithm with applications to churn prediction. IEEE Transactions on Evolutionary Computation 7(6):532-545

2. Baesens B, Verstraeten G, Van den Poel D, Egmont-Peterson M, Van Kenhove P, Vanthienen J (2004) Bayesian network classifiers for identifiying the slope of the customer lifecycle of long-life customers. European Journal of Operational Research 156(2):508-523

3. Behara RS, Fisher WW, Lemmink JG (2002) Modelling and evaluating service quality measurement using neural networks. International Journal of Operations and Production Management 22(10):1162-1185

4. Berg D (2007) Bankruptcy prediction by generalized additive models. Applied Stochastic Models in Business and Industry 23(2):129-143

5. Bloemer JM, Brijis T, Vanhoof K, Swinnen G (2003) Comparing complete and partial classification for identifying customers at risk. International Journal of Research in Marketing 20(2):117-131

6. Bose I, Chen X (2009) Quantitative models for direct marketing: A review from systems perspective. European Journal of Operational Research 195(1):1-16

7. Bose I, Chen X (2015) Detecting the migration of mobile service customers using fuzzy clustering. Information \& Management 52(2):227-238

8. Boser BE, Guyon IM, Vapnik V (1992) A training algorithm for optimal margin classifiers. In: Fifth Annual Workshop on Computational Learning Theory, Pittsburg, pp 114-152

9. Breiman L (1996) Bagging predictors. Machine Learning 24(2):123-140 
10. Buckinx W, Van den Poel D (2005) Customer base analysis: Partial defection of behaviorally loyal clients in a non-contractual FMCG retail setting. European Journal of Operational Research 164(1):252-268

11. Burez J, Van den Poel D (2007) CRM at a pay-TV company: using analytical models to reduce customer attrition by targeted marketing for subscription services. Expert Systems with Applications 32(2):277-288

12. Burges C (1998) A tutorial on support vector machines for pattern recognition. Data Mining and Knowledge Discovery 2(2):121-167

13. Chen ZY, Fan ZP, Sun M (2012) A hierarchical multiple kernel support vector machine for customer churn prediction using longitudinal behavioral data. European Journal of Operational Research 223(2):461-472

14. Chiang D, Wang Y, Lee S, Lin C (2003) Goal-oriented sequential pattern for network banking and churn analysis. Expert Systems with Applications 25(3):293-302

15. Cortes C, Vapnik V (1995) Support-vector networks. Machine Learning 20(3):273-297

16. Coussement K, De Bock KW (2013) Customer churn prediction in the online gambling industry: the beneficial effect of ensemble learning. Journal of Business Research 66(9):1629-1636

17. Coussement K, Van den Poel D (2008) Churn prediction in subscription services: An application of support vector machines while comparing two parameter-selection techniques. Expert Systems with Applications 34(1):313-327

18. Crespo F, Weber R (2005) A methodology for dynamic data mining based on fuzzy clustering. Fuzzy Sets and Systems 150(2):267-284

19. Crone SF, Lessmann S, Stahlbock R (2006) The impact of preprocessing on data mining. an evaluation of classifier sensitivity in direct marketing. European Journal of Operational Research 173(3):781-800

20. Cronin JJ, Brady MK, Hule GT (2000) Assessing the effects of quality, value, and customer satisfaction on customer behavioural intentions in service environments. Journal of Retailing 76(2):193-218

21. Datta P, Masand B, Mani PR, Li B (2000) Automated cellular modelling and prediction on a large scale. Artificial Intelligence Review 14(6):485-502

22. De Bock K, Van den Poel D (2012) Reconciling performance and interpretability in customer churn prediction using ensemble learning based on generalized additive models. Expert Systems with Applications 39(8):6816-6826

23. De Bock K, Coussement K, Van den Poel D (2010) Ensemble classification based on generalized additive models. Computational Statistics \& Data Analysis 54(6):1535-1546

24. Farquad M, Ravi V, Raju S (2014) Churn prediction using comprehensible support vector machine: An analytical CRM application. Applied Soft Computing 19:31-40

25. Fayyad U, Piatetski-Shapiro G, Smith P (1996) From data mining to knowledge discovery in databases. AI Magazine 17(3):37-54

26. Ferreira JB, Vellasco M, Pacheco MA, Barbosa CH (2004) Data mining techniques on the evaluation of wireless churn. In: Proceedings of the $12^{\text {th }}$ European Symposium on Artificial Neural Networks (ESANN), pp 483-488

27. García DL, Vellido A, Nebot À (2007) Customer continuity management as a foundation for churn data mining. Technical report LSI-07-2-R, Universitat Politècnica de Catalunya (UPC), Barcelona, Spain

28. Gilbert R (1989) Mobility barriers and the value of incumbency. Handbook of Industrial Organisation 1:475-535

29. Glady N, Baesens B, Croux C (2008) Modeling churn using customer lifetime value. European Journal of Operational Research 197(1):402-411

30. Gonçalves Curty R, Zhang P (2011) Social commerce: Looking back and forward. Proceedings of the American Society for Information Science and Technology 48(1):1-10 
31. Gür-Ali O, Aritürk U (2014) Dynamic churn prediction framework with more effective use of rare event data: The case of private banking. Expert Systems with Applications 41(17):78897903

32. Guyon I, Elisseeff A (2003) An introduction to variable and feature selection. The Journal of Machine Learning Research 3(1):1157-1182

33. Hadden J (2008) A customer profiling methodology for churn prediction. PhD thesis, Cranfield University, UK

34. Hadden J, Tiwari A, Roy R, Ruta D (2007) Computer-assisted customer churn management: State-of-the-art and future trends. Computers and Operations Research 34(10):2902-2917

35. Haenlein M, Kaplan AM (2012) The impact of unprofitable customer abandonment on current customers exit, voice, and loyalty intentions: an empirical analysis. Journal of Services Marketing 26(6):458-470

36. Haenlein M, Kaplan AM, Schoder D (2006) Valuing the real option of abandoning unprofitable customers when calculating customer lifetime value. Journal of Marketing 70(3):5-20

37. Ho TK (1998) The random subspace method for constructing decision forests. IEEE Transactions on Pattern Analysis and Machine Intelligence 20(8):832-844

38. Ho Ha S, Min Bae S, Chan Park S (2002) Customers' time-variant purchase behaviour and corresponding marketing strategies: an online retailer's case. Computers and Industrial Engineering 43(4):801-820

39. Hsieh N (2004) An integrated data mining and behavioural scoring model for analysing bank customers. Expert Systems with Applications 27:623-633

40. Hsu C, Chang C, Lin C (2008) A practical guide to support vector classification. Technical report, Department of Computer Science, National Taiwan University, Taiwan

41. Huang BQ, Kechadi MT, Buckley B (2009) Customer churn prediction for broadband internet services. In: T B Pedersen MKM, Tjoa M (eds) DaWaK 2009, LNCS 5691, Springer-Verlag, Berlin, pp 229-243

42. Huang BQ, Kechadi MT, Buckley B (2012) Customer churn prediction in telecommunications. Expert Systems with Applications 39(1):1414-1425

43. Huang Y, Kechadi T (2013) An effective hybrid learning system for telecommunication churn prediction. Expert Systems with Applications 40(14):5635-5647

44. Hung S, Yen DC, Wang HY (2006) Applying data mining to telecom churn management. Expert Systems with Applications 31(3):512-524

45. Hwang H, Jung T, Suh E (2004) An LTV model and customer segmentation based on customer value: a case study on the wireless telecommunication industry. Expert Systems with Applications 26(2):181-188

46. Jenamani M, Mohapatra PK, Ghose S (2003) A stochastic model of e-customer behaviour. Electronic Commerce Research and Applications 2(1):81-94

47. Jones MA, Mothersbaugh DL, Beatty SE (2000) Switching barriers and repurchase intentions in services. Journal of Retailing 70(2):259-270

48. Jones MA, Mothersbaugh DL, Beatty SE (2002) Why customers stay: measuring the underlying dimensions of services switching costs and managing their differential strategic outcomes. Journal of Business Research 55(6):441-450

49. Jonker J, Piersma N, Van den Poel D (2004) Joint optimization of customer segmentation and marketing policy to maximize long-term profitability. Expert Systems with Applications $27(2): 159-168$

50. Keramatia A, Jafari-Marandi R, Aliannejadi M, Ahmadian I, Mozaffari M, Abbasi U (2014) Improved churn prediction in telecommunication industry using datamining techniques. Applied Soft Computing 24:994-1012

51. Kim H, Yoon C (2004) Determinants of subscriber churn and customer loyalty in the Korean mobile telephony market. Telecommunications Policy 28(9-10):751-765 
52. Kim K, Jun C, Lee J (2014) Improved churn prediction in telecommunication industry by analyzing a large network. Expert Systems with Applications 41(15):65756584

53. Kim MK, Park MC, Jeong DH (2004) The effects of customer satisfaction and switching barrier on customer loyalty in Korean mobile telecommunication services. Telecommunications Policy 28(2):145-159

54. Kisioglu P, Topcu YL (2010) Applying Bayesian belief network approach to customer churn analysis: a case study on the telecom industry of Turkey. Expert Systems with Applications 38(6):7151-7157

55. Klemperer P (1987) Markets with consumer switching cost. The Quarterly Journal of Economics 102(2):375-394

56. Kumar D, Ravi V (2008) Predicting credit card customer churn in banks using data mining. International Journal of Data Analysis Techniques and Strategies 1(1):4-28

57. Langley P (2000) Crafting papers on machine learning. In: Langley P (ed) 17th International Conference on Machine Learning (ICML 2000), Stanford University, pp 1207-1216

58. Larivière B, Van den Poel D (2005) Predicting customer retention and profitability by using random forests and regression forests techniques. Expert Systems with Applications 29(2):472484

59. Lee TS, Chiu CC, Chou YC, Lu CJ (2006) Mining the customer credit using classification and regression tree and multivariate adaptive regression splines. Computational Statistics and Data Analysis 50(4):1113-1130

60. Lemmens A, Croux C (2006) Bagging and boosting classification trees to predict churn. Journal of Marketing Research 43(2):276-286

61. Lessmann S, Voß S (2009) A reference model for customer-centric data mining with support vector machines. European Journal of Operational Research 199(1):520-530

62. Lima E, Mues C, Baesens B (2010) Monitoring and backtesting churn models. Expert Systems with Applications 38(1):975-982

63. Lima EO (2009) Domain knowledge integration in data mining for churn and customer lifetime value modelling: New approaches and applications. PhD thesis, University of Southampton, Faculty of Law, Arts and Social Sciences, Southampton, UK

64. Lisboa PJ, Edisbury B, Vellido A (2000) Business Applications of Neural Networks. World Scientific Publishing Co

65. Liu D, Shih Y (2005) Hybrid approaches to product recommendation based on customer lifetime value and purchase references. The Journal of Systems and Software 77(2):181-191

66. Liu D, Shih Y (2005) Integrating AHP and data mining for product recommendation based on customer lifetime value. Information \& Management 42(3):387-400

67. Liu H, Motoda H (2007) Computational Methods of Feature Selection. Chapman and Hall / CRC Data Mining and Knowledge Discovery Series

68. Madden G, Savage SJ, Coble-Neal G (1999) Subscriber churn in the australian ISP market. Information Economics and Policy 11:195-207

69. Miguéis V, Camanho A, Falcão e Cunha J (2013) Customer attrition in retailing: An application of multivariate adaptive regression splines. Expert Systems with Applications 40(16):6225-6232

70. Mihelis G, Grigoroudis E, Siskos Y, Politis Y, Malandrakis Y (2001) Customer satisfaction measurement in the private bank sector. European Journal of Operational Research 130(2):347-360

71. Mozer MC, Wolniewicz R, Grimes DB, Johnson E, Kaushansky H (2000) Predicting subscriber dissatisfaction and improving retention in the wireless telecommunications industry. IEEE Transactions on Neural Networks 11(3):690-696

72. Neslin SA, Gupta S (2006) Defection detection: Improving predictive accuracy of customer churn models. Journal of Marketing Research 43(2):204-211 
73. Ng K, Liu H (2000) Customer retention via data mining. Artificial Intelligencie Review $16(4): 569-590$

74. Nie G, Zhang L, Li X, Shi Y (2006) The analysis on the customers churn of charge email based on data mining. In: Sixth IEEE International Conference on Data Mining (ICDM), Springer-Verlang, Hong Kong, China, pp 843-847

75. Nie G, Wang G, Zhang P, Tian Y, Shi Y (2009) Finding the hidden pattern of credit card holder's churn: a case of China. In: Computational Science - ICCS 2009, Springer-Verlag, Berlin, pp 561-569

76. Nie G, Rowe W, Zhang L, Tian Y, Shi Y (2011) Credit card churn forecasting by logistic regression and decision tree. Expert Systems with Applications 38(12):15,273-15,285

77. Osei-Bryson KM (2004) Evaluation of decision trees: a multi criteria approach. Computers and Operations Research 31(11):1933-45

78. Pal SK, Ghosh A (2004) Soft computing data mining. Information Sciences 163(1-3):5-12

79. Patterson MP, Smith T (2003) A cross-cultural study of switching barriers and propensity to stay with service providers. Journal of Retailing 79(2):107-120

80. Pfeifer PE, Carraway RL (2000) Modeling customer relationships as Markov chains. Journal of Interactive Marketing 14(2):43-55

81. Prinzie A, Van den Poel D (2006) Investigating purchasing-sequence patterns for financial services using Markov, MTD and MTDg models. European Journal of Operational research 170(3):710-34

82. Provost P, Fawcett T, Kohavi R (2000) The case against accuracy estimation for comparing induction algorithms. In: 15th International Conference on Machine Learning (ICML 1998), Morgan Kaufman, Madison, Wisconsin, pp 445-453

83. Ranaweera C, Neely A (2003) Some moderating effects on the service quality-customer relation link. International Journal of Operations and Production Management 23(2):230-248

84. Rygielski J, Wang J, Yen DC (2002) Data mining techniques for customer relationship management. Technology in Society 24(4):483-502

85. Shearer C (2000) The CRISP-DM model: the new blueprint for data mining. Journal of Data Warehousing 5(4):13-22

86. Shin HW, Sohn SY (2004) Segmentation of stock trading customers according to potential value. Expert Systems with Applications 27(1):27-33

87. Slater SF, Narver JC (2000) Intelligence generation and superior customer value. Journal of the Academy of Marketing Science 28(1):120-127

88. Slotnick SA, Sobel MJ (2005) Manufacturing lead - time rules: Customer retention versus tardiness costs. European Journal of Operational Research 163(3):825-856

89. Sun Z, Bebis G, Miller R (2004) Object detection using feature subset selection. Pattern Recognition 37(11):2165-2176

90. Suryadi K, Gumilang S (2008) Actionable decision model in customer churn monitoring based on support vector machines technique. In: $9^{t h}$ Asia Pacific Industrial Engineering and Management Systems Conference, Bandung, Indonesia

91. Tiwari A, Hadden J, Turner C (2010) A new neural network based customer profiling methodology for churn prediction. In: ICCSA 2010, Springer-Verlag, Berlin, chap IV, pp 358-369

92. Tsai CF, Lu YH (2009) Customer churn prediction by hybrid neural networks. Expert Systems with Applications 36(10):12,547-12,553

93. Vafeiadis T, Diamantaras K, G S, Chatzisavvas K (2015) A comparison of machine learning techniques for customer churn prediction. Simulation Modelling Practice and Theory 55:1-9

94. Van den Poel D (2003) Predicting mail-order repeat buying: which variables matter? Tijdschrift voor Economie and Management 48(3):371-403

95. Van den Poel D, Laraviére B (2004) Customer attrition analysis for financial services using proportional hazard models. European Journal of Operational research 157(1):196-217 
96. Vellido A, Lisboa PJ, Vaughan J (1999) Neural networks in business: a survey of applications (1992-1998). Expert Systems with Applications 17(1):51-70

97. Verbeke W, Dejaeger K, Martens D, Hur J, Baesens B (2011) New insights into churn prediction in the telecommunication sector: A profit driven data mining approach. European Journal of Operational Research 218:211-219

98. Verbeke W, Martens D, Baesens B (2014) Social network analysis for customer churn prediction. Applied Soft Computing 14, part C:431446

99. Verbraken T, Verbeke W, Baesens B (2014) Profit optimizing customer churn prediction with Bayesian network classifiers. Intelligent Data Analysis 18(1):3-24

100. Verhoef PC, Donkers B (2001) Predicting customer potential vualue, an application in the insurance industry. Decision Support Systems 32(2):189-99

101. Verhoef PC, Spring PN, Hoekstra JC, Leeflang PS (2003) The commercial use of segmentation and predictive modelling techniques for database marketing in the Netherlands. Decision Support Systems 34(4):471-81

102. Wang G, Liu L, Peng Y, Nie G, Kou G, Shi Y (2010) Predicting credit card holder churn in banks of China using data mining and MCDM. In: IEEE / WIC / ACM International Conference on Web Intelligence and Intelligent Agent Technology (WI-IAT), pp 215-218

103. Wei CP, Chiu LT (2002) Turning telecommunications call details to churn preduction: a data mining approach. Expert Systems with Applications 23(2):103-12

104. Witten IH, Frank E (2005) Data Mining: Practical Machine Learning Tools and Techniques, $2^{\text {nd }}$ edn. Morgan Kaufman, San Francisco

105. Wu D (2009) Supplier selection: A hybrid model using DEA, decision tree and neural network. Expert Systems with Applications 36(5):9105-9112

106. Xiao J, Xiao Y, Huang A, Liu D, Wang S (2015) Feature-selection-based dynamic transfer ensemble model for customer churn prediction. Knowledge and Information Systems 43(1):29 51

107. Yan L, Wolniewicz RH, Dodier R (2004) Predicting customer behaviour in telecommunications. IEEE Intelligent Systems 19(2):50-58

108. Yeswanth V, Vimal Raj V, Saravanan M (2011) Evolutionary churn predition in mobile networks using hybrid learning. In: Proceedings of the $24^{\text {th }}$ International Florida Artificial Intelligence Research Society Conference (FLAIRS), Florida, USA, pp 471-476

109. Zhao Y, Li B, Li X, Liu W, Ren S (2005) Customer churn prediction using improved one-class support vector machine. In: Li X, Wang S, Yang-Dong Z (eds) Advanced Data Mining and Applications, Springer, Lecture Notes in Computer Science, Vol.3584, pp 300-306

\section{Appendix}

The detailed tables of publications are reported in this appendix, following the description reported in section 3.2.

[Tables 2 to 14 , to be placed here] 


\section{Figure Captions}

Fig 1 Commercial development alternatives in mature markets. Left) the figure shows the main axis of the development of commercial value in a mature market environment: on one side, Customer Continuity Management and Customer Development -aspects that complement and configure the so-called Customer Value Management- and, on the other side, the development of selective strategies of high value customers acquisition. Right) the figure shows the customer-focused policies that can be developed for each of the defined strategic axes.

Fig 2 Stages in a client's life-cycle. The figure shows the generated value -ordinate axis- of three illustrative customer profiles -gold, silver, bronze- during their time of relationship with the company -abscissa axis-. Moreover, the figure shows the stages of customer-company interactions and the basic commercial aspects to solve in each one of the stages.

Fig 3 Customer life-cycle management model: Customer Continuity Management. The figure shows both a) prevention policies integrated in the ordinary customer management (upper part of the diagram), formed by the excellence in service quality, the creation of positive switching barriers and the development of proactive bonding policies, and b) the specific therapy policies for customer deflection (lower part of the diagram), which requires the creation of reactive retention policies, proactive recovery policies and a segmented retention island.

Fig 4 Stages of the predictive model building process ([21]).

Fig 5 Abandonment prediction methods in recent literature. Left: overall summary. Right: summary of literature published over the period 2009-2015.

Fig 6 Abandonment prediction methods by field of application. Left: Distribution by field of application. Right: Detail on the type of applied methodology. 
Figure 1

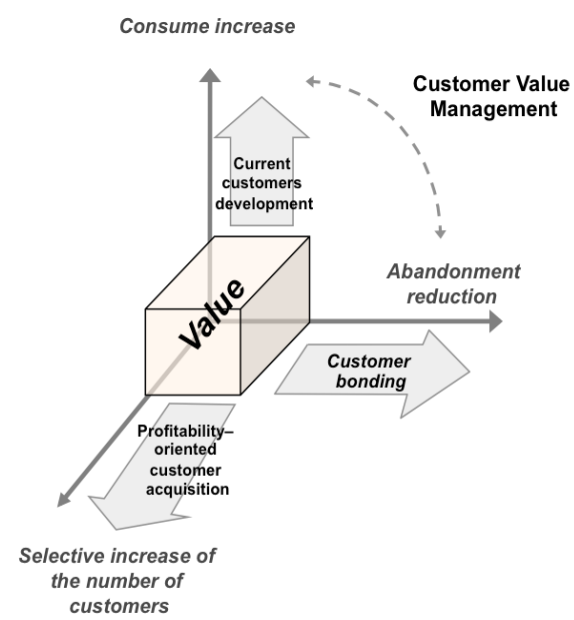

Increasing value axes

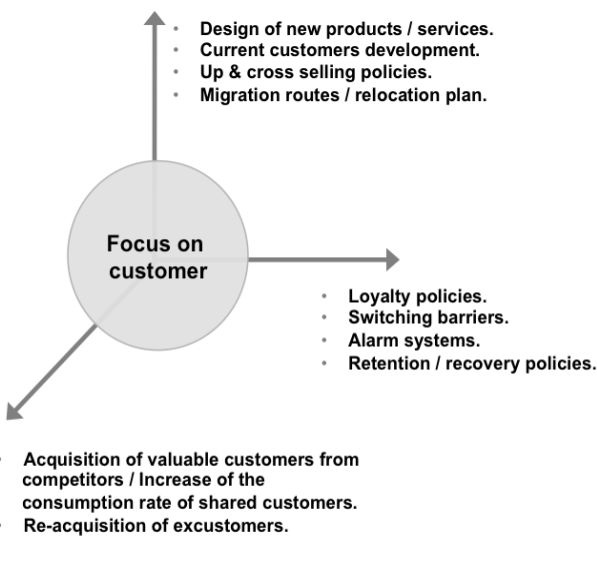

Guided commercial decisions design 


\section{Figure 2}

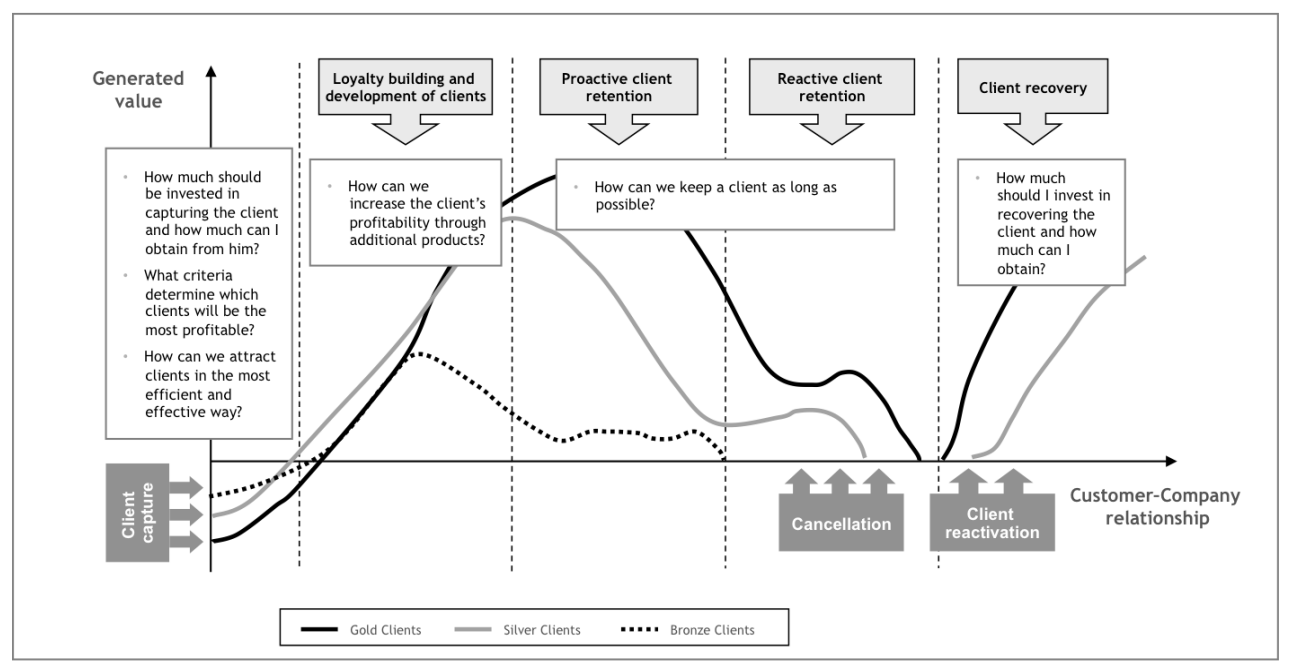


Figure 3

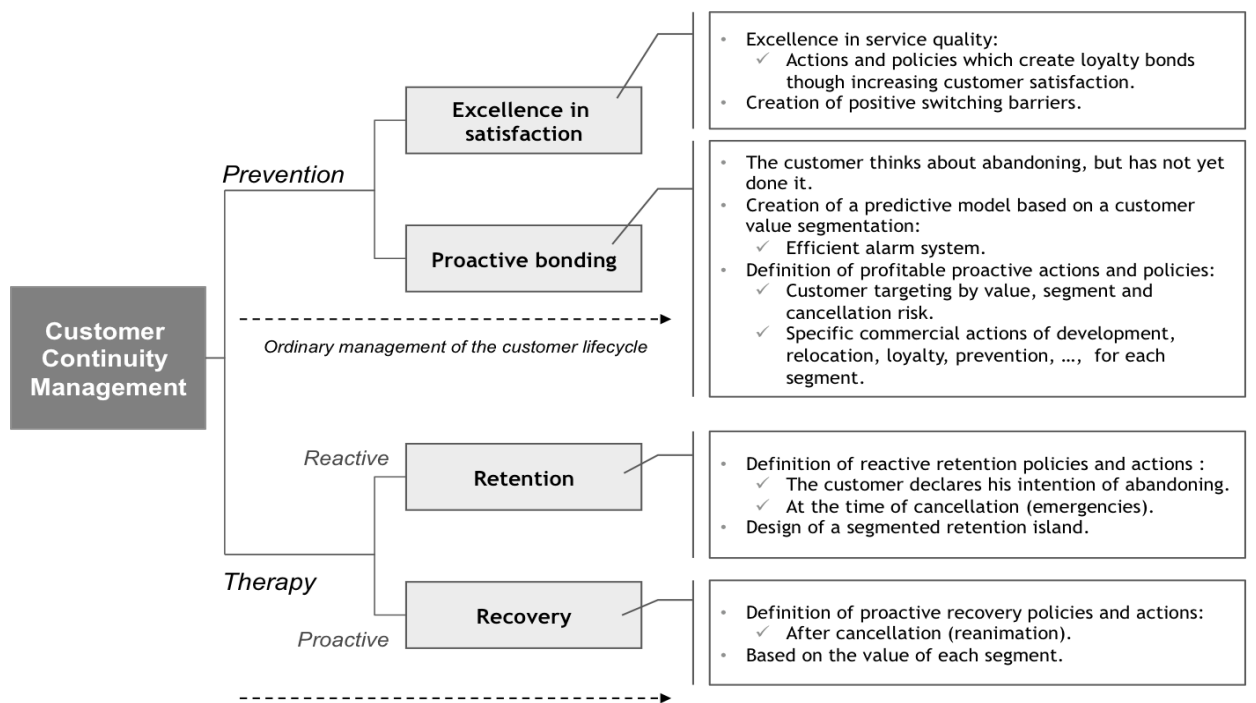

Specific management of predicted and acknowledged

cancellations 
Figure 4

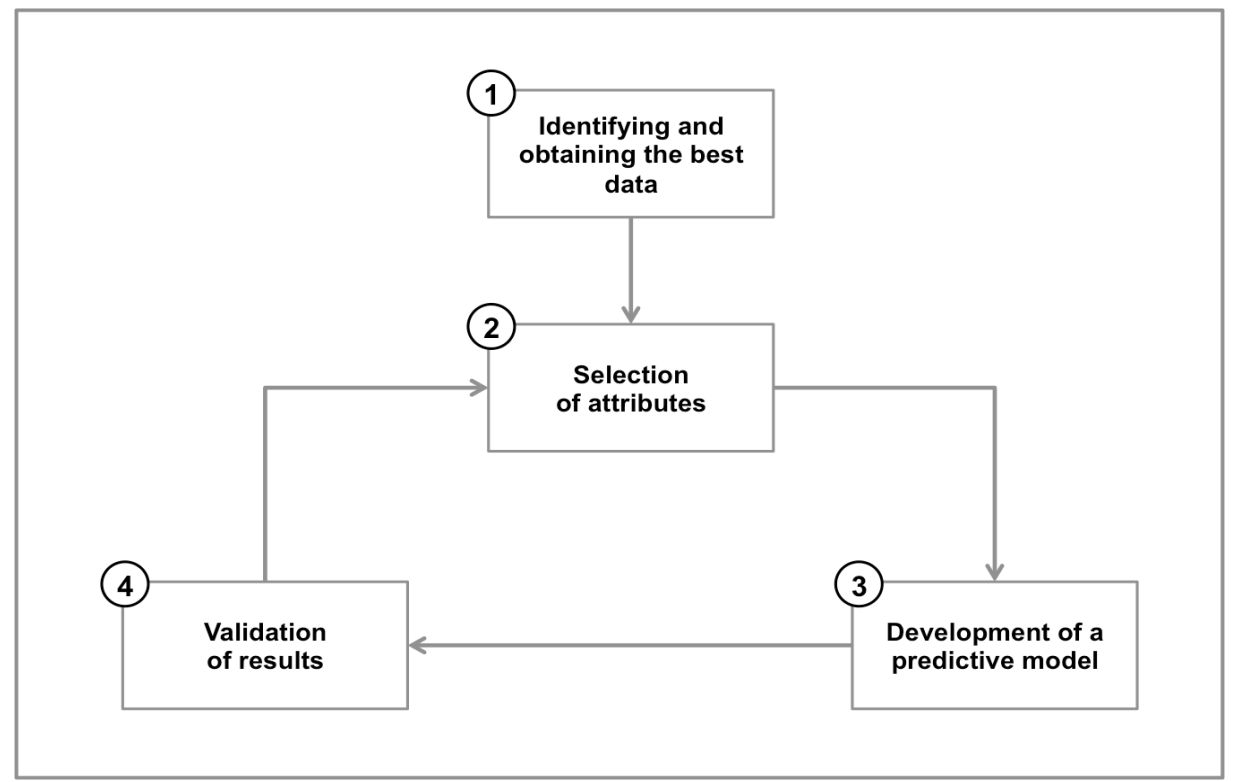


Figure 5
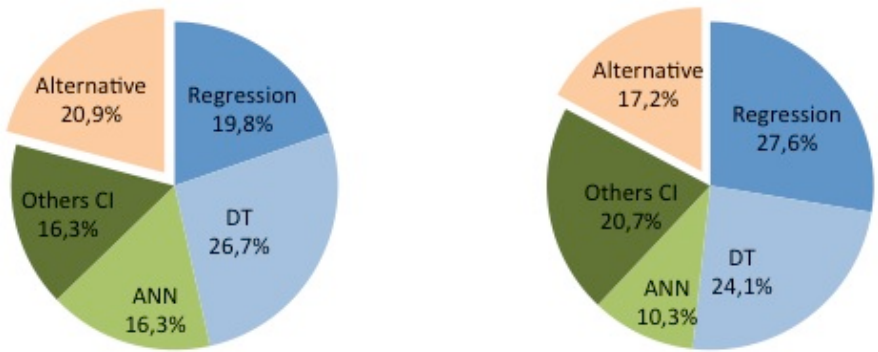
Figure 6
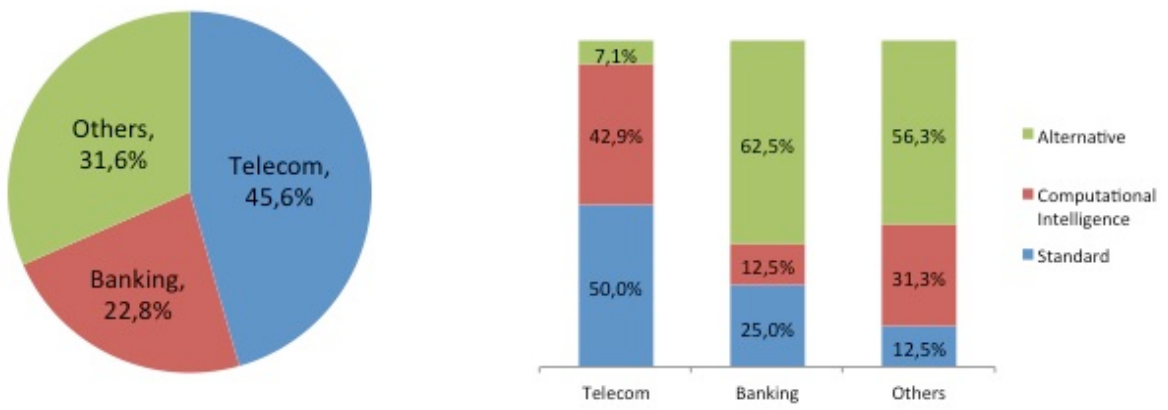
Table 1 Summary of Tables 2 to 14, located in the Appendix section. From left to right, it is structured first by application area and then by category of predictive model (as in stage 3 of Section 3; the "mixed" category includes studies in which methods from different categories have been used). References are listed in the righthand column. Studies that applied quantitative attribute selection (stage 2) methods are identified with symbol "* ", while studies that applied explicit validation (stage 4) methods are identified with symbol " $\dagger$ ".

\begin{tabular}{|c|c|c|}
\hline Application Area & Method Category & References \\
\hline \multirow{4}{*}{ Telecommunications } & Standard & $\begin{array}{l}{[68]^{*},[71]^{\dagger},[73]^{* \dagger},[103],[1],[26]^{\dagger},[45]^{* \dagger},[51],[72]^{*},[109],[44]^{*},} \\
{[60],[105]^{\dagger},[63]^{\dagger},[62]^{* \dagger},[97]^{*},[108],[50]^{*},[93]^{\dagger}}\end{array}$ \\
\hline & $\mathrm{CI}$ & $\begin{array}{l}{[68]^{*},[71]^{\dagger},[1],[26]^{\dagger},[45]^{* \dagger},[72]^{*},[109],[44]^{*},[90],[33],[92]^{\dagger},} \\
{[105]^{\dagger},[63]^{\dagger},[54],[97]^{*},[108],[13],[50]^{*},[106]^{*},[93]^{\dagger},[7]}\end{array}$ \\
\hline & Alternative & {$[105]^{\dagger},[23]^{\dagger},[97]^{*},[108],[106]^{*},[93]^{\dagger}$} \\
\hline & Mixed & {$\left[\begin{array}{l}{[68]^{*},[71]^{\dagger},[1],[26]^{\dagger},,[45]^{* \dagger},[72]^{*},[109],[44]^{*},[105]^{\dagger},[63]^{\dagger},[97]^{*},} \\
{[108]^{*},[50]^{*},[93]^{\dagger}}\end{array}\right.$} \\
\hline \multirow{4}{*}{ Banking } & Standard & {$[100],[59]^{*},[29]^{\dagger},[56]^{* \dagger},[102]^{\dagger},[76]^{\dagger},[31]^{* \dagger}$} \\
\hline & CI & {$[86],[39],[29]^{\dagger},[56]^{* \dagger},[102]^{\dagger},[24],{ }^{* \dagger},[106]^{*}$} \\
\hline & Alternative & {$[14]^{*},[95],[58]^{\dagger},[81]^{\dagger},[59]^{*},[56]^{* \dagger},[106]^{*}$} \\
\hline & Mixed & {$[59]^{*},[29]^{\dagger},[56]^{* \dagger},[102]^{\dagger},[106]^{*}$} \\
\hline \multirow{4}{*}{ Others } & Standard & {$[10]^{\dagger},[69]^{* \dagger},[94]^{*},[74],[17]^{* \dagger},[11]^{\dagger},[41],[61]^{* \dagger}$} \\
\hline & CI & {$[38],[2],[10]^{\dagger},[91],[3],[49],[17]^{* \dagger},[41],[61]^{* \dagger},[13]^{\dagger}$} \\
\hline & Alternative & {$[10]^{\dagger},[66]^{*},[23]^{\dagger},[17]^{* \dagger},[23]^{\dagger},[80],[46],[88],[11]^{\dagger},[16]^{* \dagger}$} \\
\hline & Mixed & {$[10]^{\dagger},[17]^{* \dagger},[11]^{\dagger},[41],[61]^{* \dagger}$} \\
\hline
\end{tabular}




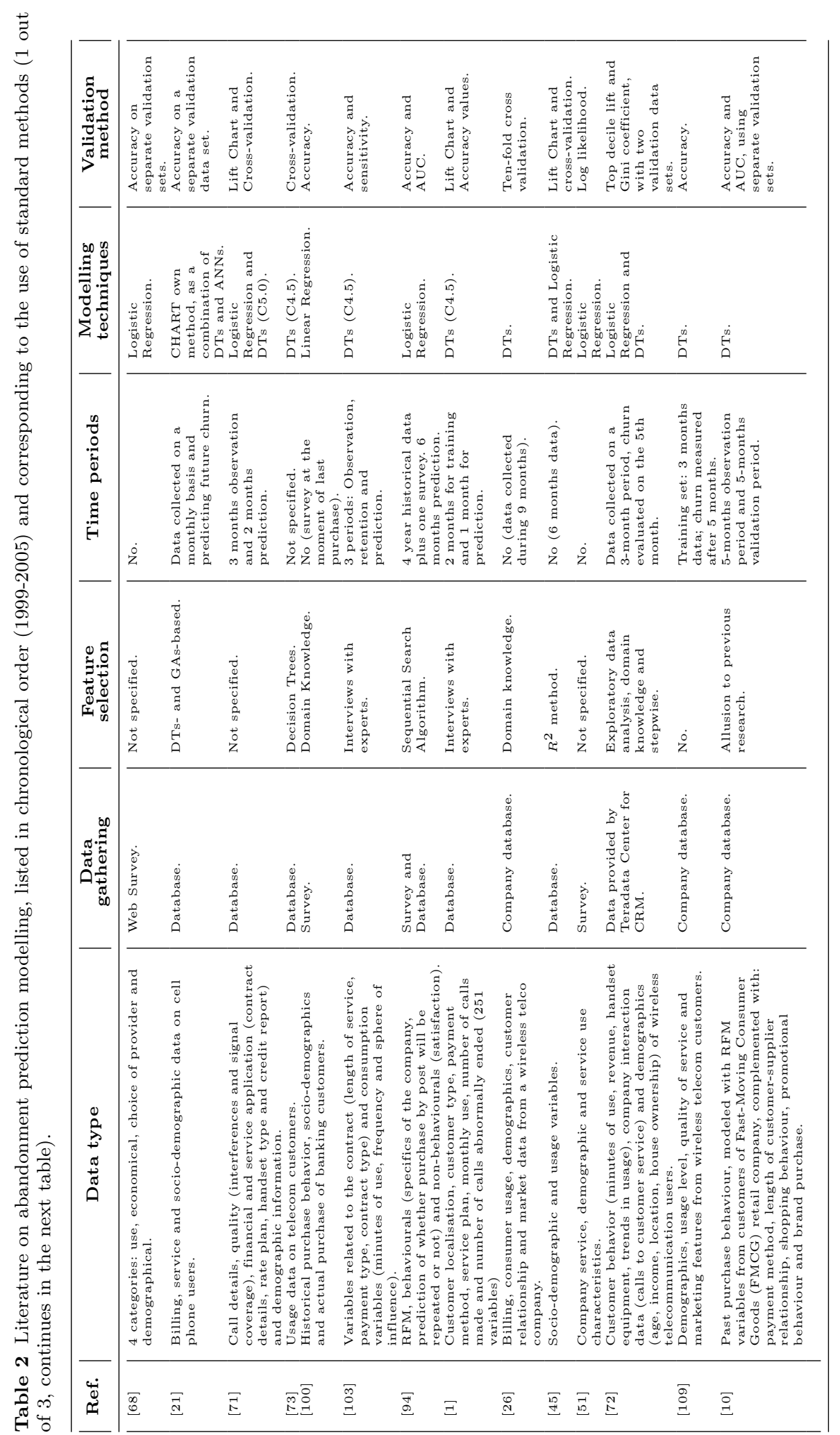




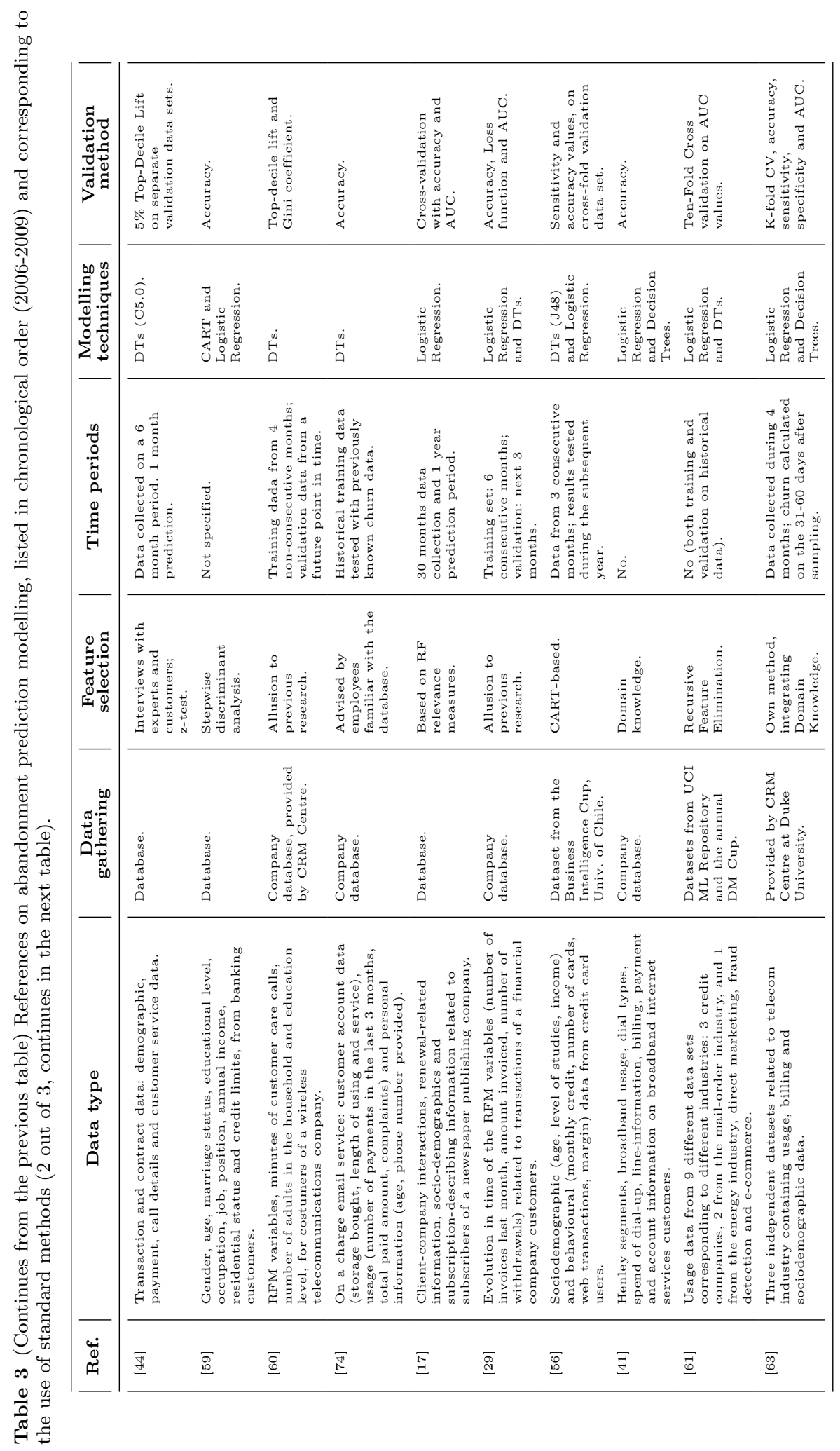




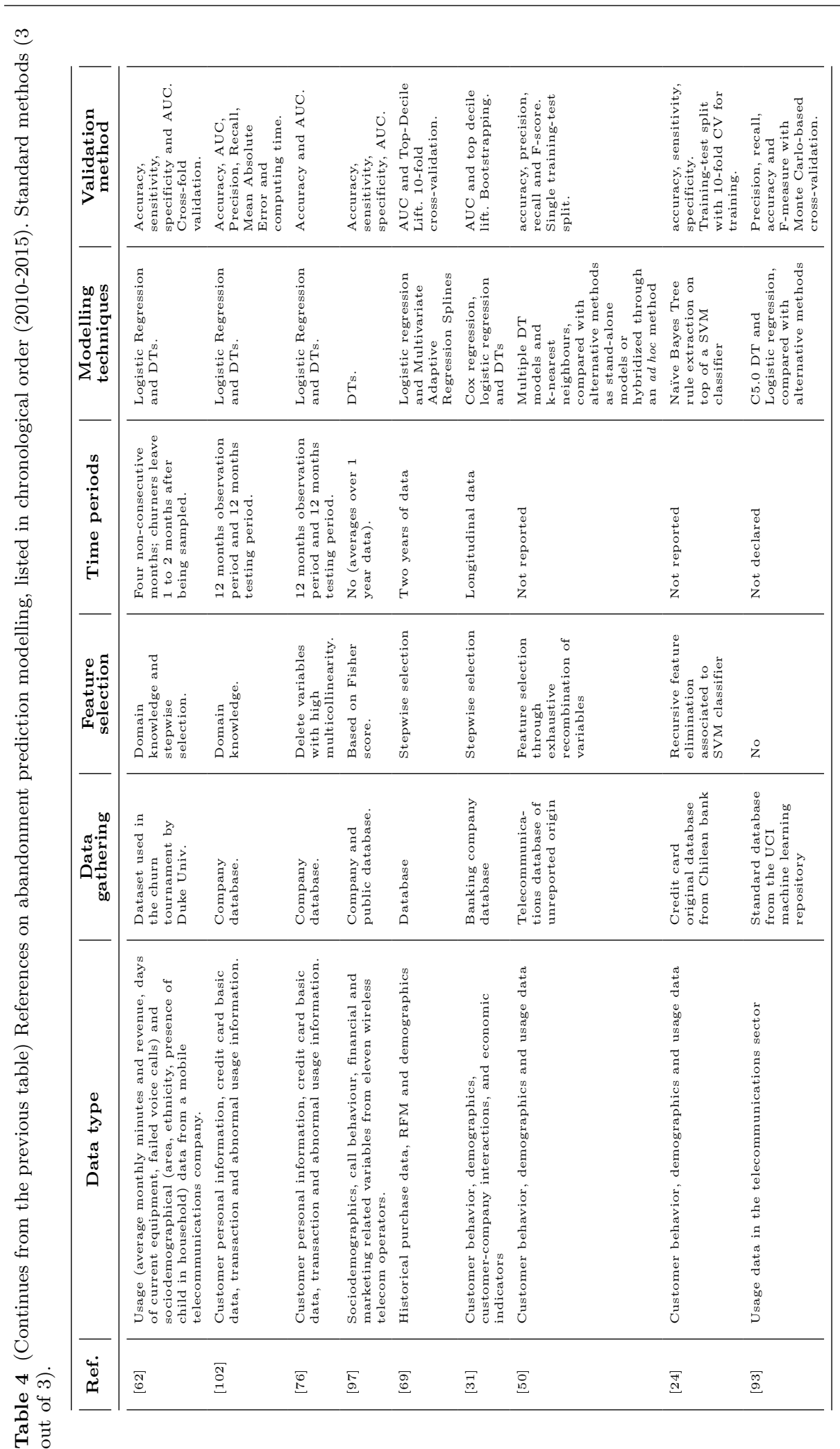




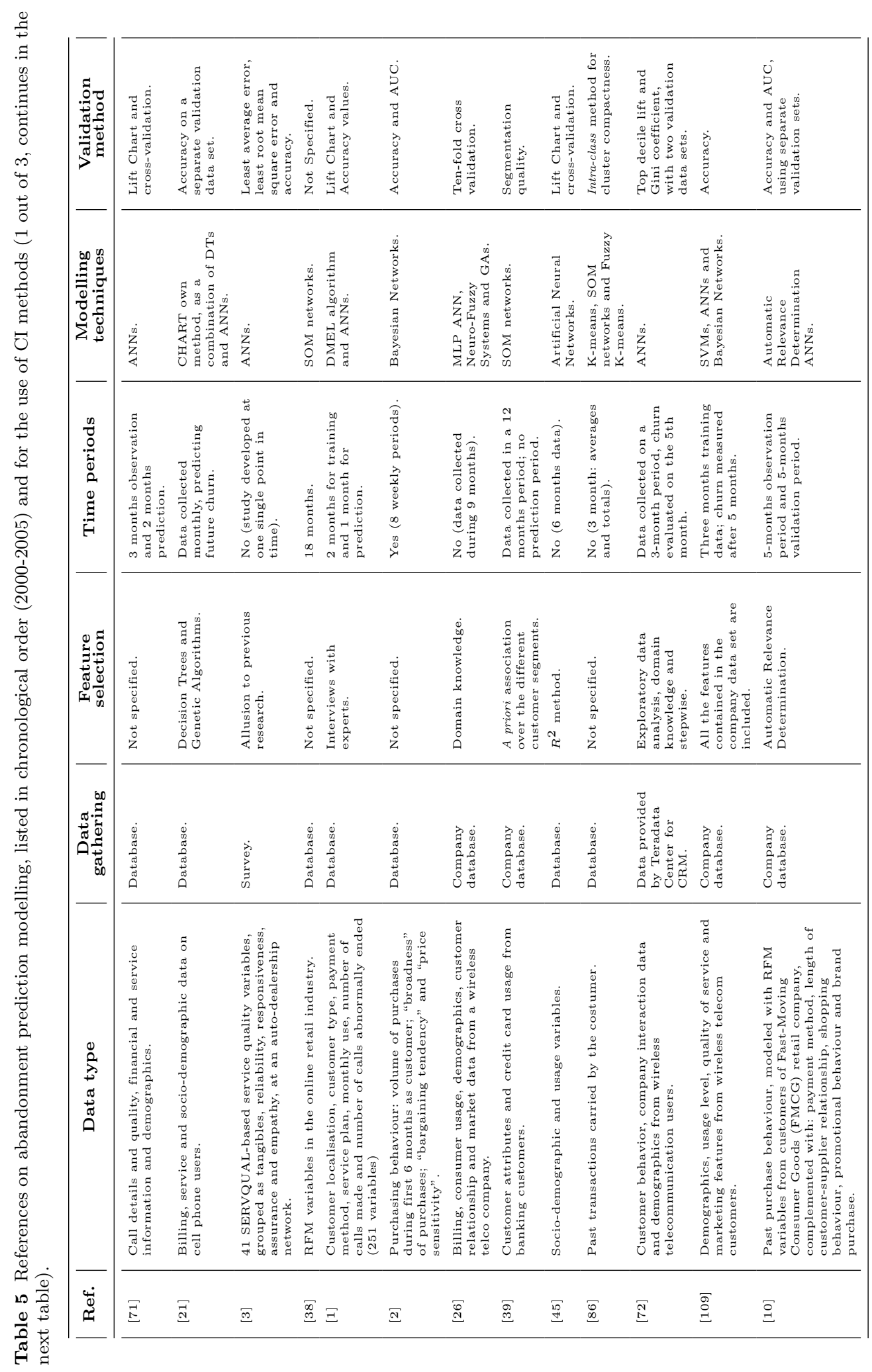




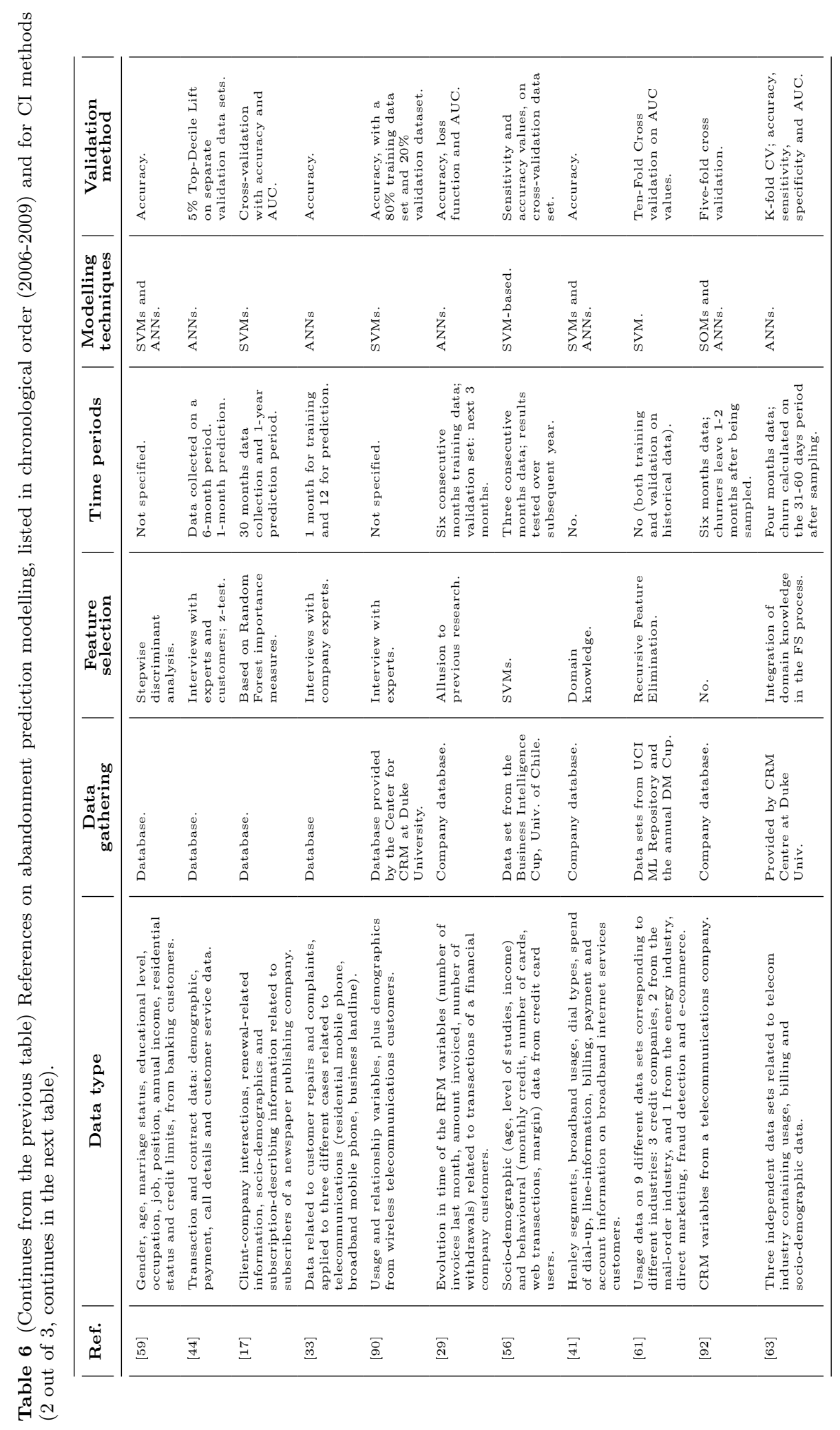




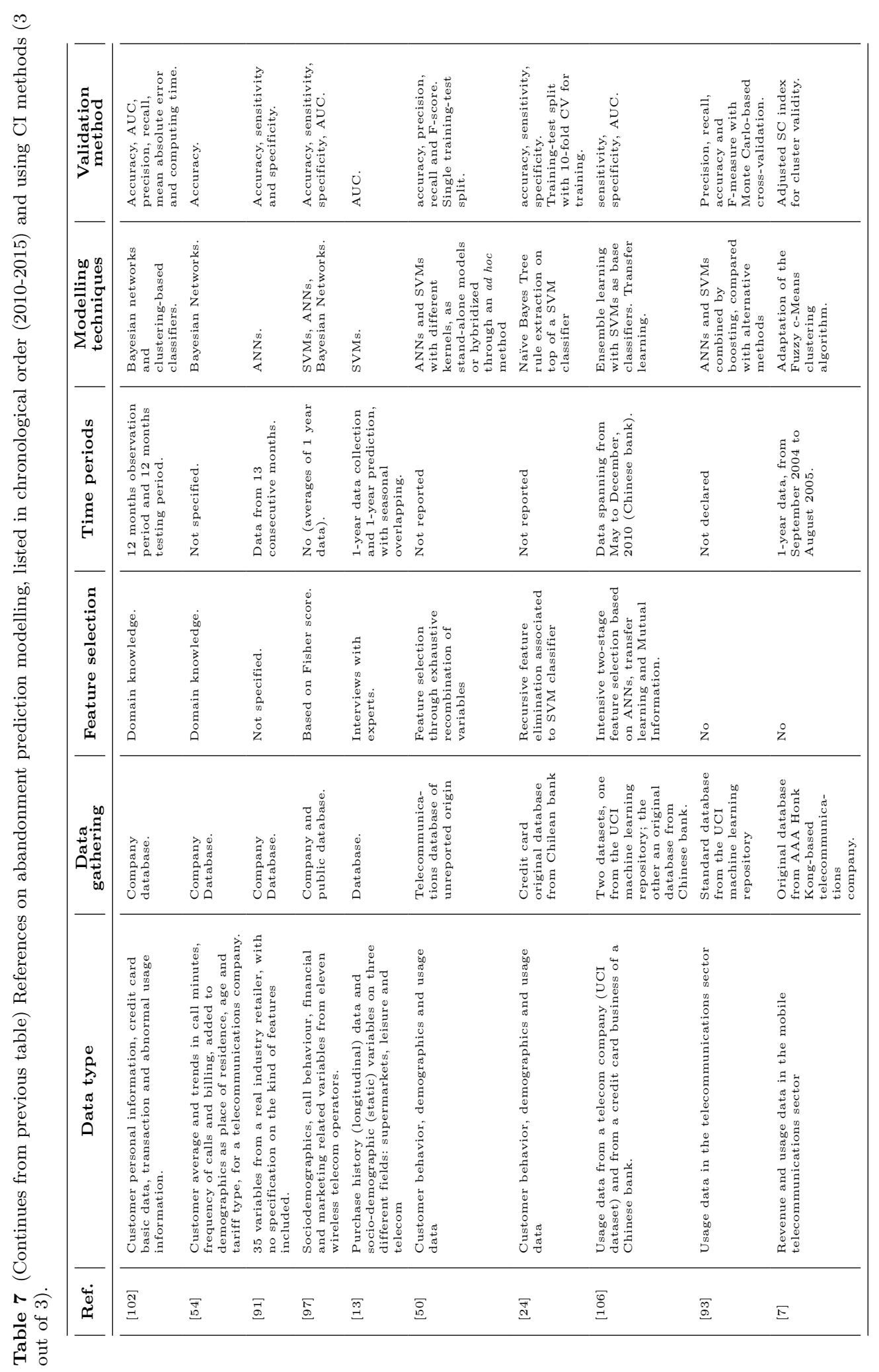




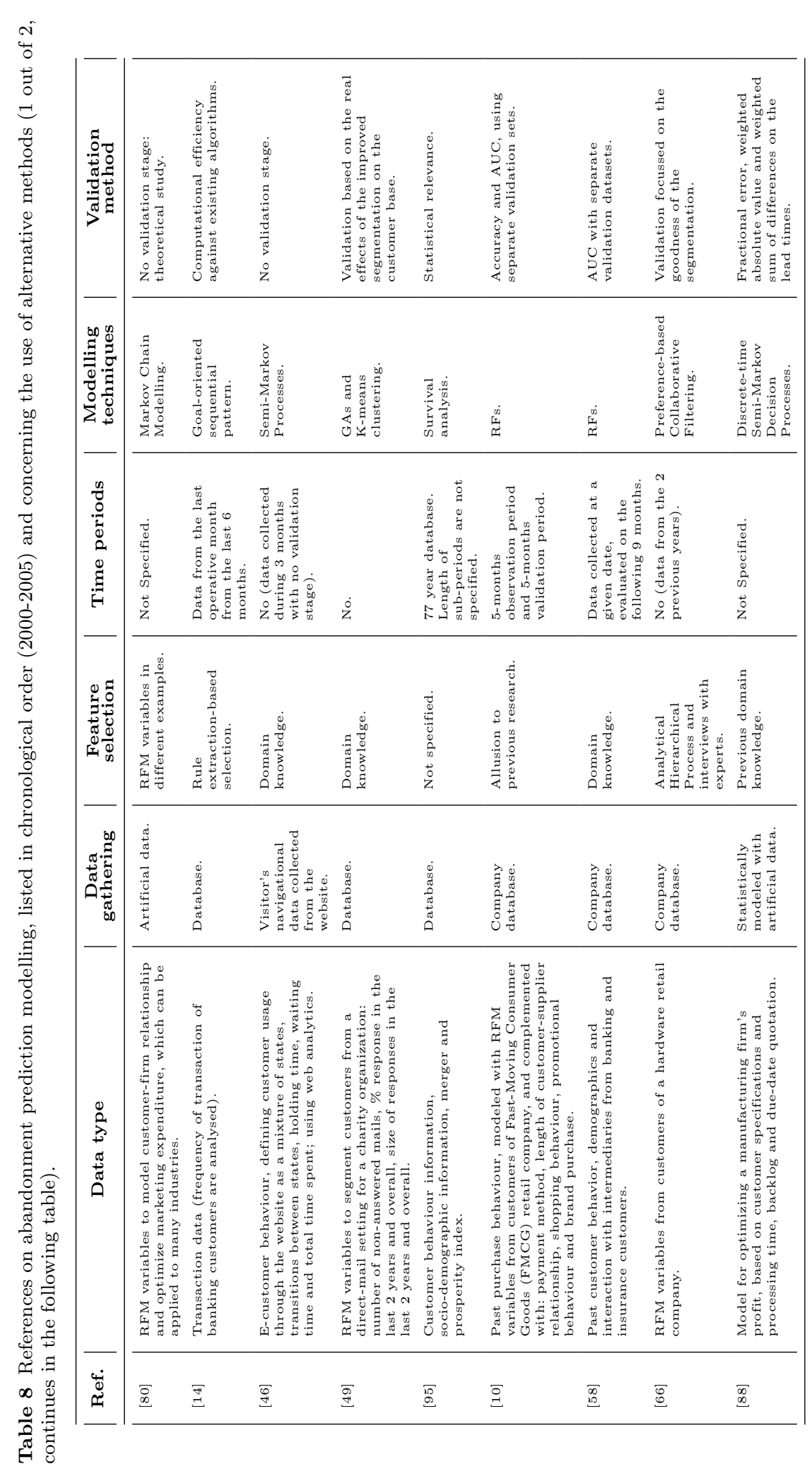




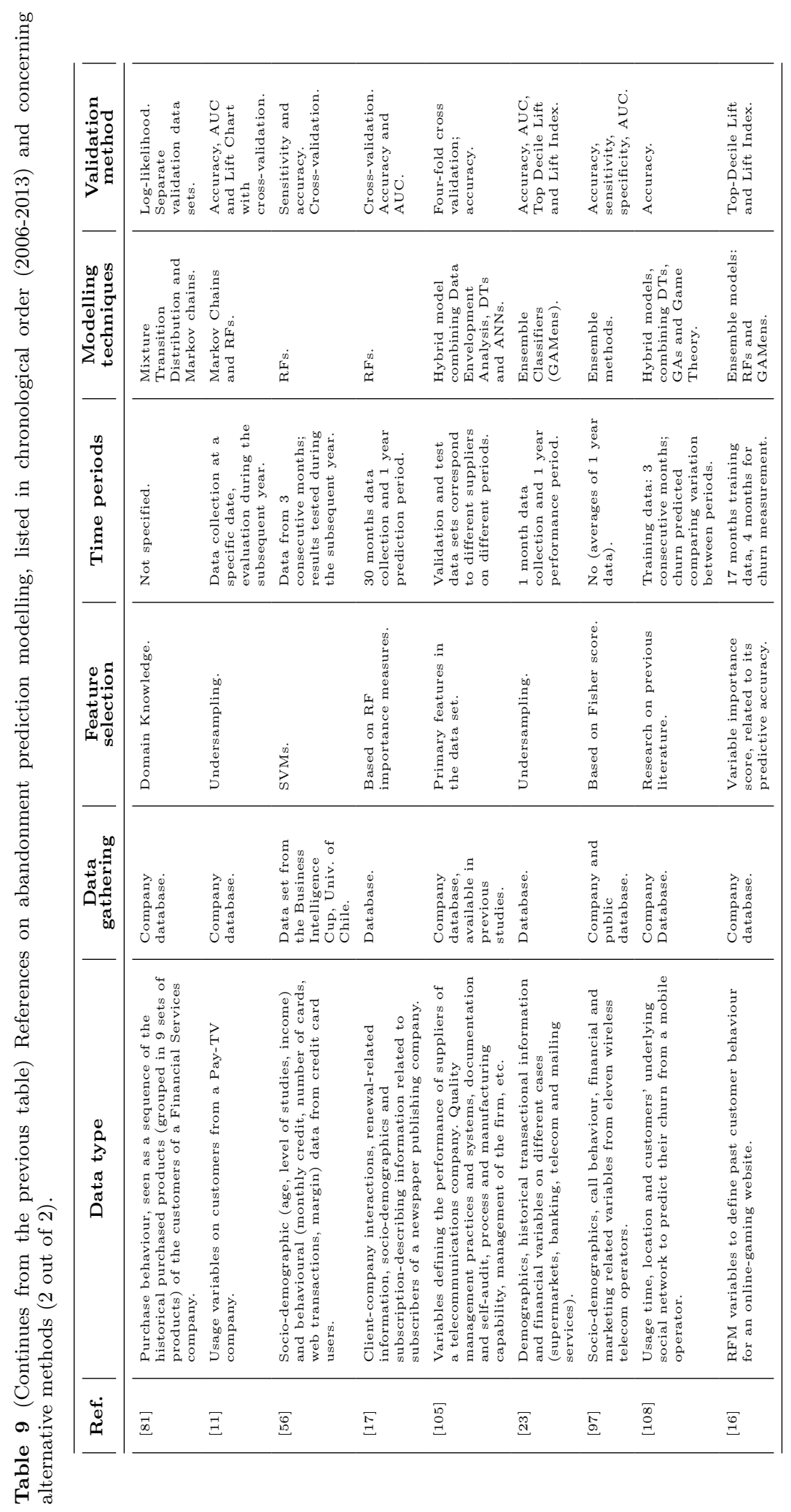


David L. García et al.

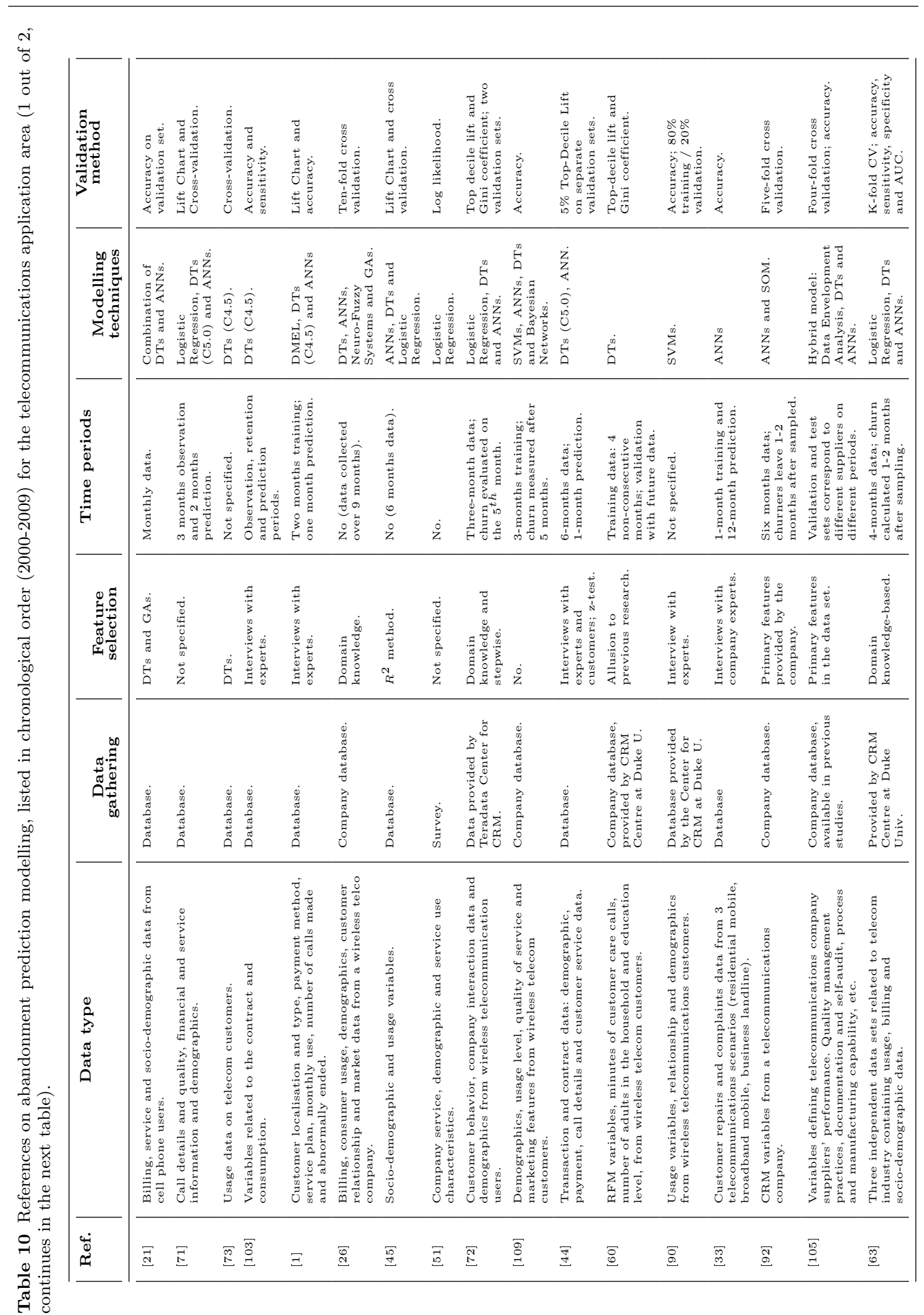




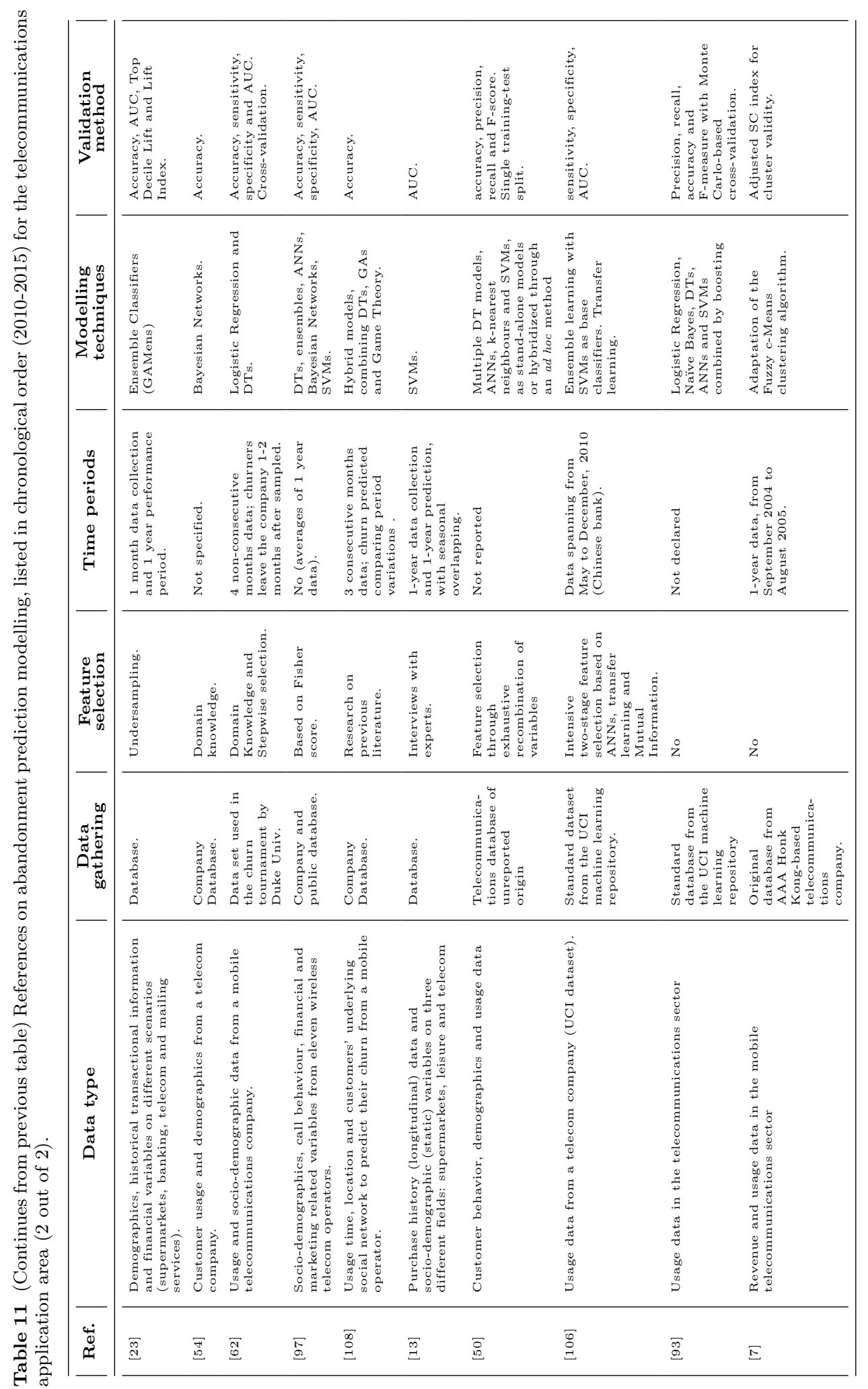




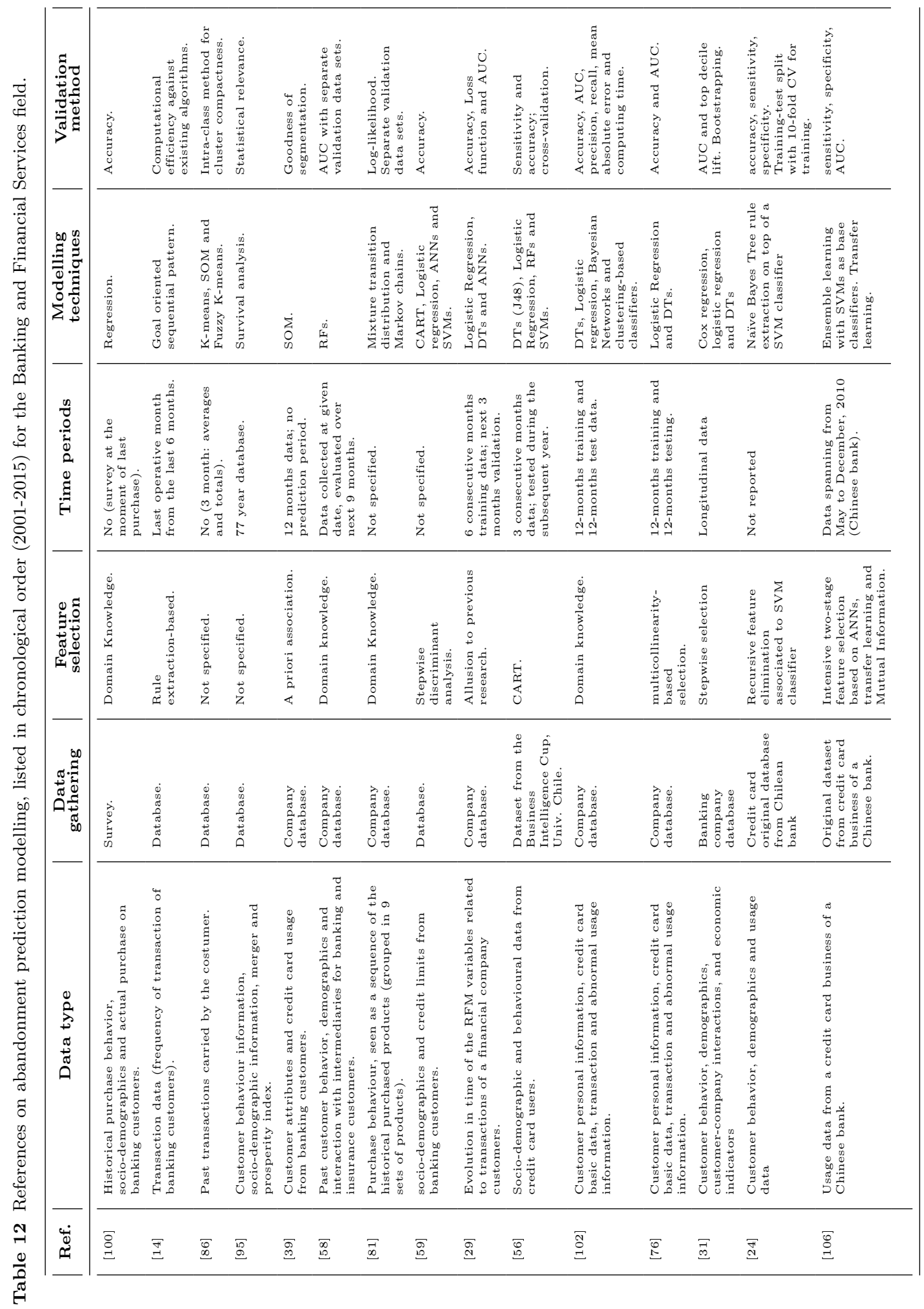




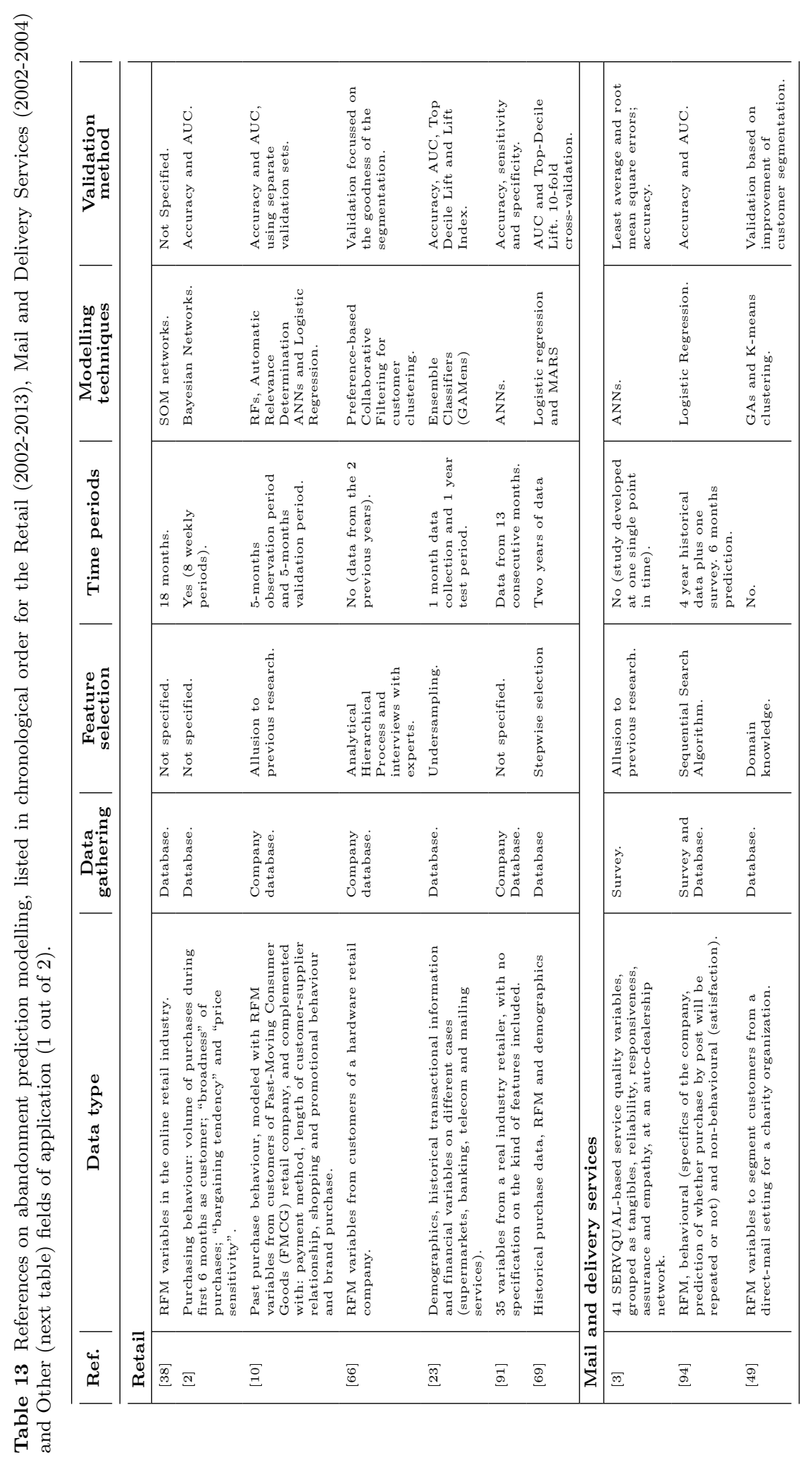




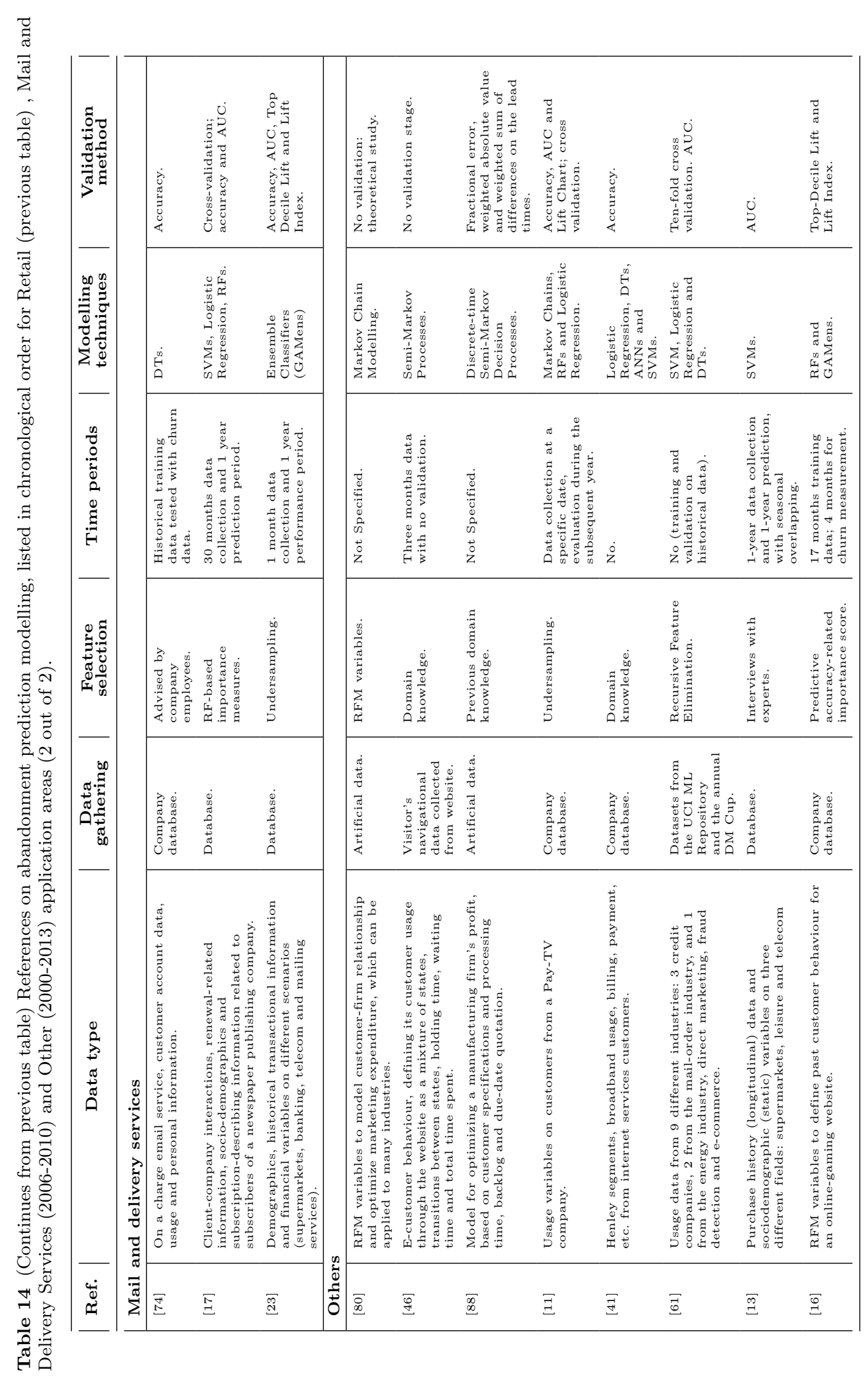

